\title{
Neuronal pentraxins as biomarkers of synaptic activity: from physiological functions to pathological changes in neurodegeneration
}

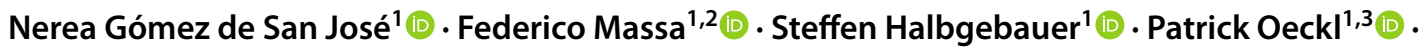 \\ Petra Steinacker ${ }^{1}$ (D) Markus Otto ${ }^{1,4}$ (iD
}

Received: 26 June 2021 / Accepted: 17 August 2021 / Published online: 30 August 2021

(C) The Author(s) 2021

\begin{abstract}
The diagnosis of neurodegenerative disorders is often challenging due to the lack of diagnostic tools, comorbidities and shared pathological manifestations. Synaptic dysfunction is an early pathological event in many neurodegenerative disorders, but the underpinning mechanisms are still poorly characterised. Reliable quantification of synaptic damage is crucial to understand the pathophysiology of neurodegeneration, to track disease status and to obtain prognostic information. Neuronal pentraxins (NPTXs) are extracellular scaffolding proteins emerging as potential biomarkers of synaptic dysfunction in neurodegeneration. They are a family of proteins involved in homeostatic synaptic plasticity by recruiting post-synaptic receptors into synapses. Recent research investigates the dynamic changes of NPTXs in the cerebrospinal fluid (CSF) as an expression of synaptic damage, possibly related to cognitive impairment. In this review, we summarise the available data on NPTXs structure and expression patterns as well as on their contribution in synaptic function and plasticity and other less well-characterised roles. Moreover, we propose a mechanism for their involvement in synaptic damage and neurodegeneration and assess their potential as CSF biomarkers for neurodegenerative diseases.
\end{abstract}

Keywords Neuronal pentraxin $\cdot$ Biomarker $\cdot$ Synapse $\cdot$ Synaptic function $\cdot$ Neurodegeneration $\cdot$ Cerebrospinal fluid

\section{Introduction}

Synapses are specialised neuronal structures that transmit nervous impulses between neurons. Synaptic transmission is fundamental to neural functions, including memory formation and learning (Südhof 2018). Synapse dysfunction is emerging as one of the earliest pathological events in many neurodegenerative disorders, and may precede neuronal loss

Markus Otto

markus.otto@uni-ulm.de; markus.otto@uk-halle.de

1 Department of Neurology, University of Ulm, Ulm, Germany

2 Department of Neuroscience, Rehabilitation, Ophthalmology, Genetics, Maternal and Child Health (DINOGMI), University of Genoa, Genoa, Italy

3 German Center for Neurodegenerative Diseases (DZNE E.V.), Ulm, Germany

4 Department of Neurology, Martin-Luther-University Halle-Wittenberg, Ernst-Grube-Str. 40, 06120 Halle (Saale), Germany
(Gong and Lippa 2010; Janezic et al. 2013; Lleó et al. 2019; Lui et al. 2016; Marttinen et al. 2015; Masliah et al. 2001). Referred to as synaptopathies, these neurodegenerative disorders are characterised by a certain degree of synaptic dysfunction and deregulation of pre- and post-synaptic proteins (Lepeta et al. 2016). The aberrant accumulation of misfolded proteins and other pathophysiological processes common to many neurodegenerative diseases, such as neuroinflammation and excitotoxicity, promote synapses dysfunction and loss. Furthermore, synapses may promote the spread of aberrant proteins via prion-like mechanisms, thus enhancing neurodegeneration (Camporesi et al. 2020; Gong and Lippa 2010; Swanson et al. 2018). In addition, studies in Alzheimer's disease (AD) found synapse loss as the pathological mechanism that best correlates with cognitive impairment (Terry et al. 1991). Thus, the ability to reliably recognise and follow synaptic damage would provide valuable knowledge on diagnosis, prognosis, staging and therapeutic response in patients. In consequence, an accurate fluid biomarker of synaptic dysfunction would be of great value for the field 
and may improve the patient's quality of life by making diagnosis faster and more accurate.

Several studies have provided data on already established $[\alpha$-synuclein, neurogranin, synaptosomal-associated protein 25 (SNAP-25), synaptotagmin-1 and neuromodulin (GAP43)] and emerging fluid biomarkers of synaptic damage [ $\beta$-synuclein, synaptic vesicle glycoprotein 2A (SV2A)] (Camporesi et al. 2020; Halbgebauer et al. 2020; Oeckl et al. 2020). Among the latter, neuronal pentraxins (NPTXs) have gained attention as they participate in synaptic plasticity (O’Brien et al. 2002, 1999; Sia et al. 2007; Xu et al. 2003) and are expressed in brain regions that are primarily affected by $\mathrm{AD}$ and other neurodegenerative pathologies (Hawrylycz et al. 2012; Uhlén et al. 2015). NPTXs might be a selective marker for the imbalance of pyramidal neuron-interneuron microcircuits, thought to underlie cognitive impairment in AD (Xiao et al. 2017). Moreover, their structural homology with pentraxins involved in the immune system (Wang et al. 2020) could indicate a role in neuroinflammation and complement-mediated synaptic pruning (Kovács et al. 2020), mechanisms involved in neurodegeneration (Swanson et al. 2018; Tenner et al. 2018). In addition, NPTXs are present in both pre-and post-synaptic compartments providing information about the status of both domains (Xu et al. 2003). Taken together, these features highlight the potential of NPTXs as markers of structural and functional synaptic deficiency in neurodegeneration.

Recent studies in cerebrospinal fluid (CSF) revealed altered NPTXs levels in several neurodegenerative disorders. Even though AD patients have been mostly investigated so far (Begcevic et al. 2018; Brinkmalm et al. 2018; Duits et al. 2018; Galasko et al. 2019; Hendrickson et al. 2015; Lim et al. 2019; Llano et al. 2017; Nilsson et al. 2021; Ringman et al. 2012; Soldan et al. 2019; Spellman et al. 2015; Swanson et al. 2016; Wildsmith et al. 2014; Xiao et al. 2017; Yin et al. 2009), some data are also available for other neurodegenerative disorders such as frontotemporal lobar degeneration (FTLD) and synucleinopathies, as well as for psychiatric disorders (Barschke et al. 2020; Boiten et al. 2020; Charbonnier-Beaupel et al. 2015; Eastwood and Harrison 2010; Moran et al. 2008; Remnestål et al. 2020; van der Ende et al. 2020, 2019). To date, measurements of NPTXs can only be performed in CSF samples, due to the insufficient assay sensitivity for a reliable quantification in blood. Given that lumbar puncture is an invasive procedure, longitudinal studies are missing. Moreover, the lack of consistency between studies may be the result of different inclusion and exclusion criteria and the absence of standardised analytical methods. Thus, prospective studies are required to drive further conclusions about the potential of these proteins as CSF and blood biomarkers of neurodegeneration.

In this review, we summarise the current knowledge about structure and expression pattern of the neuronal pentraxin family and discuss its physiological role in synaptic plasticity and its hypothetical involvement in pathological synaptic degeneration. Finally, we assess their potential as CSF biomarkers and drug targets for different neurodegenerative disorders and give some insights into their speculative role in other diseases of the central nervous system (CNS).

\section{Neuronal pentraxins: a subfamily of highly conserved pentraxins}

NPTXs are a family of three proteins (neuronal pentraxin 1 (NPTX1), neuronal pentraxin 2 (NPTX2) and neuronal pentraxin receptor (NPTXR)), part of the pentraxin family. Pentraxins are an evolutionary and highly conserved family of proteins from invertebrates to humans, which highlights their important role in complex organisms. They are humoral pattern recognition receptors that modulate the crossroad between innate and adaptive immune responses (Garlanda et al. 2005). They are defined by a C-terminal pentraxin domain, consisting of roughly 200 amino acids (AA), with a 8 AA structural motif known as the pentraxin sequence (His$\mathrm{X}$-Cys-X-Ser/Thr-Trp-X-Ser, where $\mathrm{X}$ is any AA) (Breviario et al. 1992; Wang et al. 2020) (Fig. 1a). Pentraxins can be classified into two groups: (1) short pentraxins [C-reactive protein (CRP) (Whitehead et al. 1983) together with serum amyloid P component (SAP) (Dowton and McGrew 1990)]; and (2) long pentraxins [pentraxin 3 (PTX3) (Lee et al. 1993), pentraxin 4 (PTX4) (Martinez de la Torre et al. 2010) and NPTXs (Dodds et al. 1997; Hsu and Perin 1995; Omeis et al. 1996)]. Short pentraxins are arranged in pentameric structures with a discoid shape (CRP-PDB ID: 1GNH; SAP_PDB ID: 1SAC) (Emsley et al. 1994; Shrive et al. 1996), however the quaternary structure of long pentraxins is unknown (Fig. 1b,c). They share the C-terminal pentraxin domain with short pentraxins, but they contain a long N-terminal domain unrelated to other proteins (Bottazzi et al. 2010) (Fig. 1a-c). In 2021, the publication of AlphaFold 2 enabled the prediction of the three-dimensional structure of NPTXs, among many other proteins (Jumper et al. 2021; Senior et al. 2020) (Fig. 1d). CRP, SAP and PTX3 participate in innate immune responses against extracellular and intracellular pathogens through activation and regulation of the complement cascade, microorganism opsonisation and agglutination. Moreover, they take part in inflammation and clearance of apoptotic cells (Bottazzi et al. 2010). NPTXs modulate synaptic function and plasticity (Xu et al. 2003), however their potential role in the immune system has been poorly described in scientific literature and is open to debate. A new study published in 2021, confirmed a role of NPTXs in synaptic pruning by activation of the complement cascade (Kovács et al. 2020). Accordingly, NPTXs may perform 
a
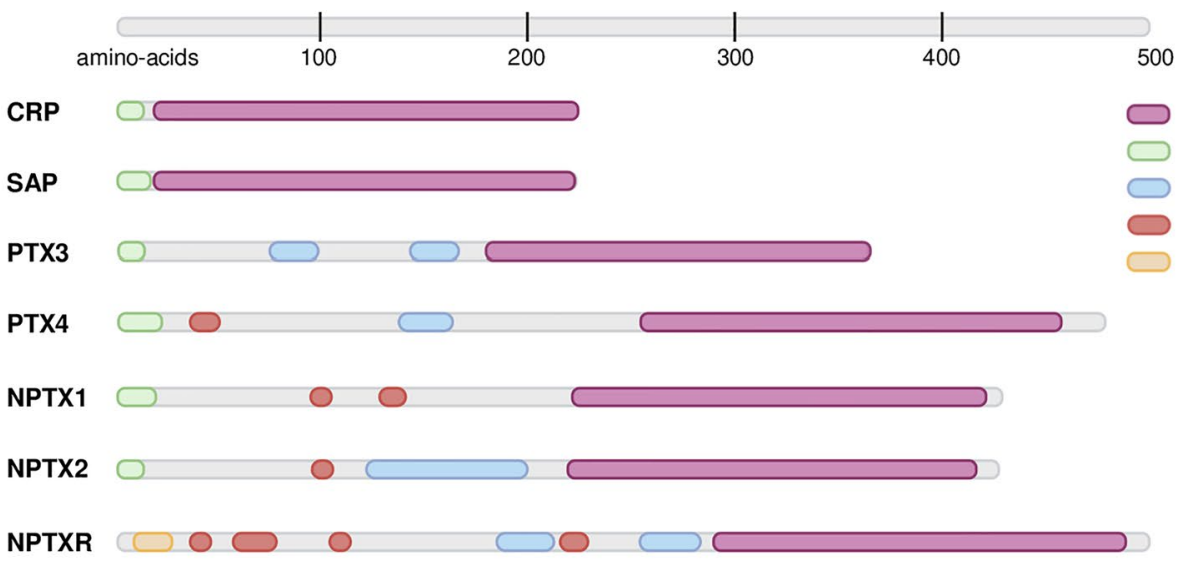

$\square$ Pentraxin domain

Signal peptide

Coiled coil region

Low complexity region

Transmembrane domain b
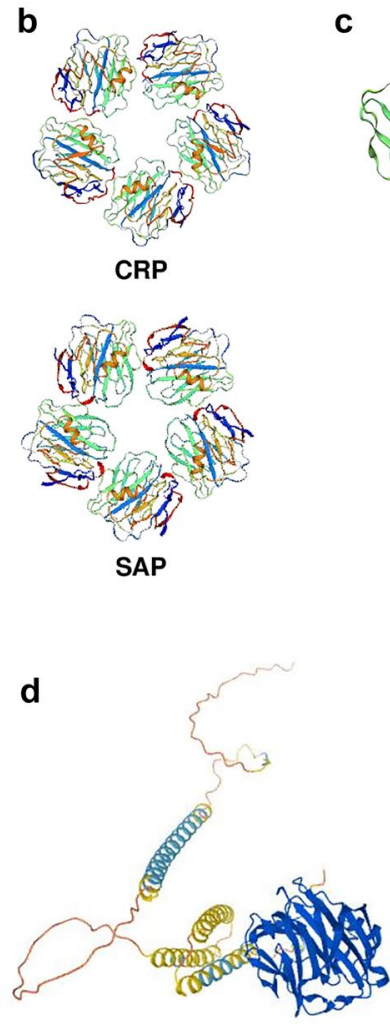

NPTX1

C

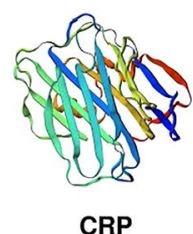

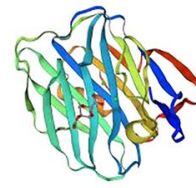

SAP

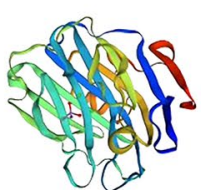

PTX3

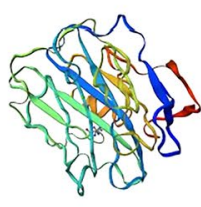

PTX4

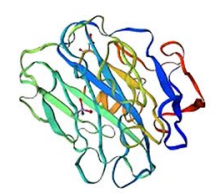

NPTX1

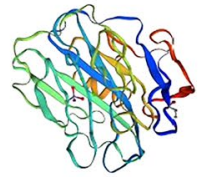

NPTX2

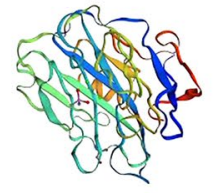

NPTXR
Fig. 1 a Sequence localisation of the protein domains of pentraxins: pentraxin domain (purple), signal peptide (green), coiled coil region (blue), low complexity region (red) and transmembrane domain (orange). Long pentraxins (PTX3-P26022, PTX4-Q96A99, NPTX1-Q15818, NPTX2-P47972 and NPTXR-O95502) share the C-terminal pentraxin domain with short pentraxins (CRPP02741 and SAP-P02743), but they contain a long N-terminal domain. Data obtained from Proteomics DB and UniProt. Created with Biorender.com $\mathbf{b}$ Experimental quaternary structure of the pentameric human CRP and SAP obtained by X-Ray diffraction. Data obtained from the Swiss-Model database (Emsley et al. 1994; Shrive et al. 1996; Waterhouse et al. 2018) c Tertiary structure of the pentraxin domain of all members of the pentraxin family. Experimental tertiary structure of the pentraxin domain of CRP, SAP and NPTX1 obtained by X-Ray diffraction, two-layered $\beta$ sheet with a flattened jellyroll topology (Emsley et al. 1994; Shrive et al. 1996; Suzuki et al. 2020). Predicted structure of the pentraxin domain of PTX3, PTX4 and neuronal pentraxins (NPTX1, NPTX2 and NPTXR) by sequence homology with NPTX1. The pentraxin domain is highly conserved within this family of proteins. Data obtained from the Swiss-Model database. d Tertiary structure of the NPTXs obtained with the Protein Structure Database AlphaFold (Senior et al. 2020). The colour code indicates the per-residue confidence score $(0-100)$ : dark blue $(>90$, very high), light blue (90-70, confident), yellow (70-50, low), orange $(<50$, very low $)$ 
some of the functions of the classical pentraxins in the brain, with additional roles in synaptic function.

\section{Expression pattern and structure of neuronal pentraxins}

\section{Neuronal pentraxin 1}

In humans, the NPTX1 gene is located on chromosome 17q25.3. Its cDNA clone sequence consists of $150 \mathrm{bp}$ 5'UTR, $1.3 \mathrm{~kb}$ coding region and $3.6 \mathrm{~kb}$ 3' UTR (Omeis et al. 1996). The coding region is divided in 5 exons and 4 introns (Gene ID: 4884). NPTX1 protein (also known as NP1) (Q15818) is a $47 \mathrm{kDa}$ secreted glycoprotein of 432 AA sequence (Schlimgen et al. 1995). It contains several domains: a peptide signal (1-22 AA), a N-terminal with two low complexity regions (98-108 AA and 129-140 AA) and a C-terminal pentraxin domain (222-428 AA) (Schmidt et al. 2018) (Fig. 1a). NPTX1 has two sites for N-glycosylation (Asn154 and Asn193) and several Cys residues. Three cysteine residues are located in the N-terminal (Cys32, Cys42 and Cys89) and are involved in disulphide bonds mediating the formation of homomeric and heteromeric assembly with NPTX2 (Xu et al. 2003). Cys256 and Cys316 form another disulphide bond within the pentraxin domain (The UniProt Consortium 2021). In 2020, the crystal structure of the pentraxin domain of NPTX1 was obtained by X-Ray Diffraction. The pentraxin domain exhibits the same structure as CRP and SAP, a two-layered $\beta$ sheet with a flattened jellyroll topology (Suzuki et al. 2020) (Fig. 1c). Since 2021, the full three-dimensional structure can be obtained using the Protein Structure Database AlphaFold (Senior et al. 2020) (Fig. 1d). NPTX1 is mainly expressed in the brain, but also present in the retina and vitreous humour, adrenal gland, rectum, and testis (Schmidt et al. 2018; Uhlén et al. 2015) (NPTX1 data available from v20.1.proteinatlas. org). Within the human brain, it is highly expressed in the cerebral cortex (including hippocampal formation), cerebellum, and amygdala (Fig. 2a). With regards to its cellular localisation in the cerebral cortex, NPTX1 is present in neuronal projections, mainly in the pre-synaptic terminal; in particular, in the mossy fibres projecting from granule cells to the dentate gyrus, in the stratum lucidum of CA3 and stratum radiatum of CA1. Moreover, it has also been detected in neuronal cell bodies, in the neuropil of entorhinal cortex and hippocampus, and in glial cells (Abad et al. 2006; Uhlén et al. 2015) (Table 1).

\section{Neuronal pentraxin 2}

The human NPTX2 gene is located on chromosome 7q22.1. Its cDNA clone sequence consists of $1.3 \mathrm{~kb}$ coding region and $1.2 \mathrm{~kb} 3$ 'UTR (Hsu and Perin 1995). The coding region is divided in 5 exons and 4 introns (Gene ID: 4885). NPTX2 protein (also known as NP2, Narp in rat and apexin/p50 in guinea pig) (P47972) is a $47 \mathrm{kDa}$ secreted glycoprotein, 431 AA long (Hsu and Perin 1995; Tsui et al. 1996). It is a calcium-dependent lectin capable of binding its ligands in a calcium-dependent manner (Tsui et al. 1996). It contains similar domains as NPTX1, a peptide signal (1-17 AA), a coiled coil motif (121-199 AA) and a low complexity region (96-109 AA) in the $\mathrm{N}$-terminal and a pentraxin domain (219-424 AA) in the C-terminal (Schmidt et al. 2018) (Fig. 1a). NPTX2 has three sites of N-glycosylation (Asn148, Asn189 and Asn393). All cysteines in the N-terminal are involved in intermolecular disulphide bonds, which are necessary and sufficient to form multimers. Cys29 and Cys 41 form the core of NPTX2 hexamer structure, whereas Cys95 intervenes in the interaction between different hexamers. Cys 253 and Cys 313 form an additional disulphide bond within the pentraxin domain (The UniProt Consortium 2021; $\mathrm{Xu}$ et al. 2003). Desheng Xu et al. (2003) proposed a cyclic multimeric structure by homology with short pentraxins (Xu et al. 2003) (Fig. 1b). Until 2021, only the structure of the pentraxin domain could be obtained by sequence homology analysis with NPTX1 (Waterhouse et al. 2018) (Fig. 1c). Nowadays, the Protein Structure Database AlphaFold can predict the full three-dimensional structure of this protein (Senior et al. 2020) (Fig. 1d). NPTX2 is the most broadly expressed of the three NPTXs. It is present in the pancreas, vitreous humour, colon, endocrine tissues (pituitary gland and adrenal gland), brain, testis, and prostate gland. Within the brain, it is mainly expressed in a subset of cells in the anterior pituitary gland and in neurons in the cerebral cortex (Schmidt et al. 2018; Uhlén et al. 2015) (NPTX2 data available from v20.1.proteinatlas.org) (Fig. 2b). Additionally, it was detected in a subpopulation of glial cells, including microglia, in post-mortem tissue of Parkinson's disease (PD) patients (Moran et al. 2008) (Table 1).

\section{Neuronal pentraxin receptor}

In humans, NPTXR is located on chromosome 22q13.1. Its cDNA clone sequence consists of $3.9 \mathrm{~kb} 3^{\prime} \mathrm{UTR}$ and $1.5 \mathrm{~kb}$ coding region (Dodds et al. 1997). The coding region is divided in 5 exons and 4 introns (Gene ID: 23,467). NPTXR (also known as NPR) (O95502) is a $53 \mathrm{kDa}$ type-II transmembrane protein with $500 \mathrm{AA}$. It is anchored to the plasmatic membrane through the N-terminal (7-29 AA). However, multiple intracellular isoforms are described (Cho et al. 2008). This protein consists of a short intracellular domain (1-7 AA), four low complexity regions in the N-terminal (38-52 AA, 58-90 AA, 106-118 AA, 218-228 AA), two coiled coil motifs (188-214 AA and 248-286 AA) and the pentraxin domain in the C-terminal (288-494 AA) (Schmidt et al. 2018) (Fig. 1a). NPTXR has three sites 
Fig. 2 2D representation according to axial, coronal and sagittal axes and 3D rendering of the areas with the highest RNA expression of NPTX1 (a), NPTX2 (b) and NPTXR (c). The gene expression data was obtained from Allen Human Brain Atlas (Hawrylycz et al. 2012). Microarray analysis of 900 anatomically defined sites of 6 patients was conducted with two different probes. The areas with a $z$ score $>1$ were considered. Regions of interest were obtained by MarSBar toolbox (Brett et al. 2002) to be overlaid to the MNI referential atlas (MRIcroGL software, https://www.nitrc.org/projects/ mricrogl) and are represented in different colours, as follows: frontal lobe (wine red), temporal lobe (purple), amygdala (light blue), hippocampus (black), cerebellum (copper), thalamus (brown), occipitaltemporal gyrus (green), insula (orange), parietal lobe (yellow), cingulate gyrus (dark blue) and parahippocampal gyrus (red). Anatomical positions: anterior (A), posterior $(\mathrm{P})$, superior $(\mathrm{S})$, inferior (I), left (L) and right (R)
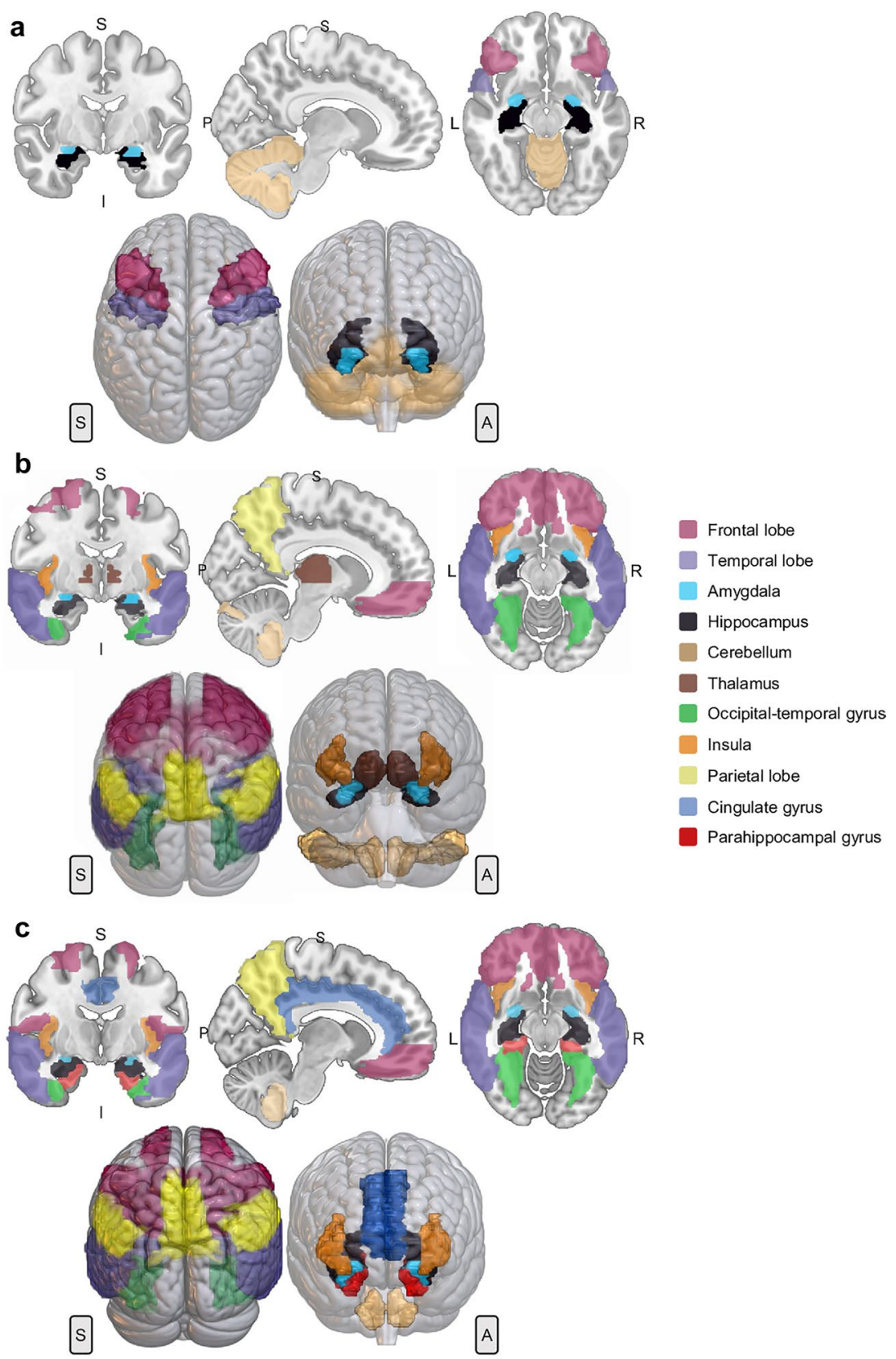

of N-glycosylation (Asn42, Asn216 and Asn463) and two cysteines, Cys322 and Cys383, which form a disulphide bond within the pentraxin domain (The UniProt Consortium 2021). Until 2021, only the structure of the NPTXR pentraxin domain could be obtained by sequence homology analysis with NPTX1 (Waterhouse et al. 2018) (Fig. 1c). Just like NPTX1 and NPTX2, the full three-dimensional structure of NPTXR can now be obtained using the software AlphaFold (Senior et al. 2020) (Fig. 1d). At present, NPTXR is proposed as the receptor for NPTX1 and NPTX2, due to their binding affinity (Dodds et al. 1997) and NPTXR's ability to recruit NPTX1 and NPTX2 to the synaptic membrane (Kirkpatrick et al. 2000). NPTXR is mainly expressed in brain in the cytoplasm and synapse of neurons and neuropil, mostly in cerebral cortex and hippocampal formation (Uhlén et al. 2015) (NPTXR data available from v20.1.proteinatlas. org) (Fig. 2c). Outside the CNS, it is localised in rectum, adrenal glands and in helper T-lymphocytes (Schmidt et al. 2018) (Table 1).

\section{Role of neuronal pentraxins in synaptic function and plasticity}

NPTXs are synaptic organizers located in the synaptic cleft. They are part of the family of extracellular scaffolding proteins, responsible for regulating the assembly of 


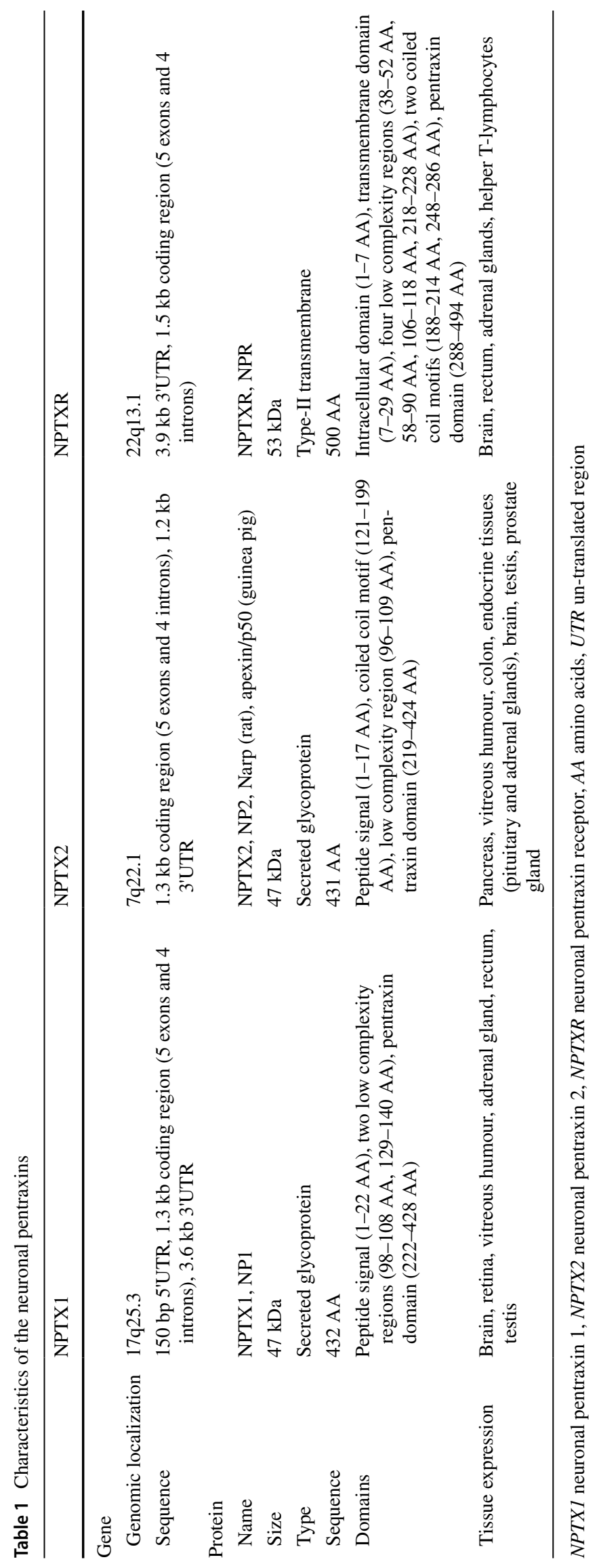


pre- and post-synaptic compartments by recruiting postsynaptic receptors (Yuzaki 2018). NPTXs play a role in synaptogenesis (Farhy-Tselnicker et al. 2017; FigueiroSilva et al. 2015; Sia et al. 2007), synaptic plasticity (O'Brien et al. 2002, 1999; Sia et al. 2007; Xu et al. 2003), homeostasis (Pribiag and Stellwagen 2014), metabotropic glutamate receptor long-term depression (LTD), synapse elimination (Cho et al. 2008), clearance of synaptic debris and toxins from neurons (Dodds et al. 1997) and neurite outgrowth (Tsui et al. 1996). Moreover, there is evidence that NPTXs are involved in intracellular processes such as mitochondrial dynamics and trafficking, and neuronal apoptosis (Clayton et al. 2012; Rahim et al. 2013; Tseng and Bixby 2011). In addition, recent studies concluded a role of NPTXs in synaptic pruning by activation of the classical complement cascade (Kovács et al. 2020) (Fig. 3a). In humans, they participate in nervous system development (Bjartmar et al. 2006; Boles et al. 2014).
NPTX1 and NPTX2 are the two soluble proteins from the neuronal pentraxin family which colocalise at synapses in the forebrain, including the neocortex (study conducted in rat) (Xu et al. 2003). NPTX1 is constitutively released from excitatory synapses and was initially described for its neuronal activity-independent synaptogenic roles (Kirkpatrick et al. 2000; Xu et al. 2003). Conversely, another study concluded an upregulation of NPTX1 expression upon reduction in neuronal activity, contributing to neuronal cell death (DeGregorio-Rocasolano et al. 2001) and mitochondrial accumulation of the apoptosis regulator BAX (Clayton et al. 2012). Moreover, NPTX1 negatively regulates excitatory synapse density through interaction with a subunit of slowrectifying-gated Kv7 potassium channel (Figueiro-Silva et al. 2015). NPTX1 is enriched in the synaptic plasma membrane and also detected in mitochondria (in accordance with its role in mitochondrial apoptosis) (Kovács et al. 2020). New data suggested astrocyte-secreted glypican-4 (GPC4) to induce NPTX1 release from pre-synaptic terminals through

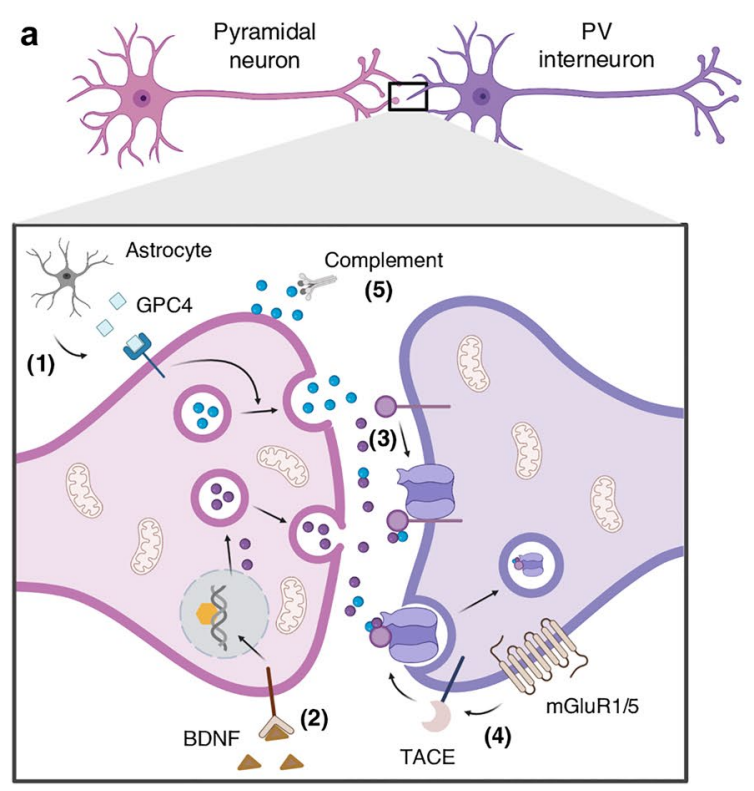

Fig. 3 Schematic illustration of the proposed mechanism for the physiological role of neuronal pentraxins (NPTXs) (a) and the hypothesised pathological mechanisms in neurodegeneration (b). a The NPTX1 release from the pre-synaptic terminal into the synaptic cleft may be modulated by the astrocyte-secreted glypican-4 (GPC4) (1), whereas NPTX2 is synthesize and release in response to neuronal activity or BNDF (2). Once in the synaptic cleft, NPTX1 and NPTX2 can form heterocomplexes and bind to NPXR, which is anchored in the post-synaptic membrane. The NPTX complex is then able to cluster and stabilise $\alpha$-amino-3-hydroxy-5-methyl-4-isoxazolepropionic acid receptor (AMPAR) in the post-synaptic membrane, modulating the excitatory drive onto parvalbumin (PV) interneurons (3). In the presence of excess of glutamate in the synaptic cleft, the mGLUR $1 / 5$ receptor is activated and the metalloprotease tumour necrosis factor-alpha converting enzyme (TACE) cleaves the transmembrane domain of NPTXR. Cleaved NPTXR and AMPAR are internalised

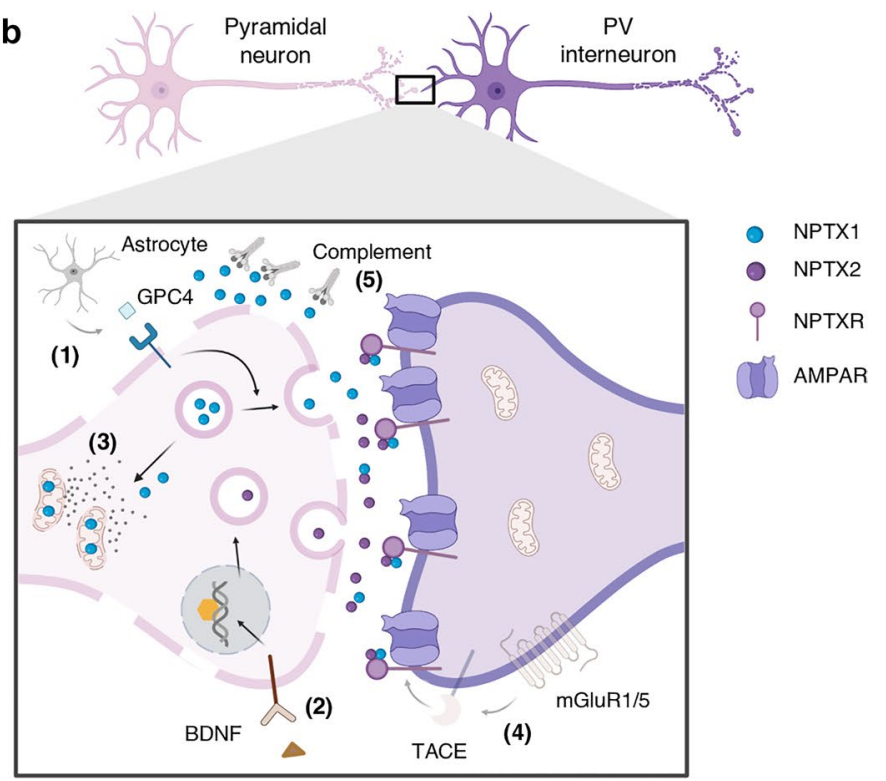

via endocytosis. This mechanism may protect against excitotoxicity (4). NPTX1 may play a role as activator of the classical complement pathway, leading to microglia-dependent apoptosis (5). b Several hypotheses could explain the deregulation of NPTXs and the excess of synaptic loss observed in neurodegeneration. The loss of astrocytic functions and reduced BDNF could lead to a decrease in synthesis and release of NPTX1 and NPTX2, respectively $(1,2)$. Under low neuronal activity, NPTX1 translocates to the mitochondria, activating BAX-dependent apoptosis and hindering the translocation of mitochondria to the pre-synaptic terminal (3). An alteration of the mechanism to detect excess of glutamate could decrease the endocytosis of NPTX complexes, leading to excitotoxicity (4). The complementmicroglia pathway activated by NPTX1 may be intensified upon neurodegenerative processes, favouring the excess synaptic loss observed in these disorders (5). Created with Biorender.com 
type 2a receptor protein tyrosine phosphatase (RPTP8) (Farhy-Tselnicker et al. 2017) (Fig. 3a-1). NPTX2 is an immediate early gene (IEG) and acts in a neuronal activitydependent manner (Tsui et al. 1996; Xu et al. 2003). As an IEG, it is rapidly and transiently expressed, and belongs to a family of genes that participate in learning, memory, and long-term plasticity (Gallo et al. 2018). It is released from the pre-synaptic terminal in response to neuronal activity, seizure (O'Brien et al. 1999), long-term potentiation (LTP) (Tsui et al. 1996) or brain-derived neurotrophic factor (BDNF) (Mariga et al. 2015). BDNF bidirectionally regulates NPTX2 expression at the transcriptional level, even in the absence of neuronal activity (Fig. 3a-2). BNDF-induced NPTX2 is required for glutamatergic synaptic transmission and LTP in mossy fibres in the dendate gyrus (Mariga et al. 2015; Wibrand et al. 2006). NPTX2 is located in the synaptic cytoplasm and plasma membrane (Kovács et al. 2020).

NPTX1 and NPTX2 are present in both pre- and postsynaptic compartments (Xu et al. 2003). Under physiological conditions, NPTX2 is mainly secreted from the pre-synaptic terminal into the synapses (Chang et al. 2010; Reti et al. 2002). After their release into the synaptic cleft, both soluble pentraxins (NPTX1 and NPTX2) become rapidly associated into heteromultimers. Those heteromultimers require $\mathrm{N}$-terminal protein-protein interactions and specific disulphide bonds, involving Cys29 and Cys95 of NPTX2. The relative ratio of the two proteins in the complex is time- and activitydependent (Xu et al. 2003). The complex can also interact with NPTXR, which is anchored in the post-synaptic membrane through its N-terminal domain (Dodds et al. 1997) (Fig. 3a-3). NPTXR knock-out (KO) mice presented 50\% reduced levels of NPTX1 and NPTX2 in the brain, indicating a possible role of NPTXR as stabilizer of NPTX1 and NPTX2 at synapses (Bjartmar et al. 2006).

The NPTX complex acts as trans-synaptic signalling molecule, regulating the activity of neurotransmitter receptors at excitatory synapses. This is supported by its colocalization with the post-synaptic density protein 95 (PSD95), a excitatory synaptic scaffolding protein; but not with glutamic acid decarboxylase, a marker of inhibitory axons (Chang et al. 2010; Cho et al. 2008; Xu et al. 2003). In particular, the complex promotes $\alpha$-amino-3-hydroxy-5-methyl4-isoxazolepropionic acid receptor (AMPAR) aggregation and stabilisation (O'Brien et al. 1999) (Fig. 3a-3). In vitro studies reported that NPTX2 has a greater effectiveness in clustering AMPAR than NPTX1, due to its N-terminal distinctive properties. In the heteromultimer, NPTX2 enhances NPTX1's clustering capability, increasing the complex's ability to aggregate AMPAR and promote synaptogenesis (Xu et al. 2003). The three NPTXs interact, directly or indirectly, with the N-terminal extracellular domain of AMPAR subunits (GluA1, GluA2, GluA3 and GluA4), via their conserved pentraxin domain (Chang et al. 2010; Cho et al.
2008; Lee et al. 2017; Sia et al. 2007; Suzuki et al. 2020). Accordingly, NPTXs act as bimodular proteins. The pentraxin C-terminal domain interacts and promotes AMPAR clustering and stabilisation, whereas the $\mathrm{N}$-terminal coiled coil domain mediates self-association.

NPTXs are enriched at excitatory glutamatergic synapses of pyramidal neurons onto parvalbumin (PV) interneurons in the mice hippocampus (Chang et al. 2010) (Fig. 3a). PV interneurons are the most common interneuron subtype in the hippocampus (Pelkey et al. 2017) and are critical regulators of prefrontal cortex-dependent behavioural responses (Ferguson and Gao 2018). They are GABAergic, fast-spiking interneurons, crucial for network synchronisation of pyramidal neurons (Hu et al. 2014) and the optimal balance of excitation/inhibition (E/I) in cortical circuits. They confer a higher level of computational complexity by modulating pyramidal neuronal gain and preventing excessive excitatory signalling (Ferguson and Gao 2018). Additionally, PV interneurons participate in the generation and maintenance of gamma oscillations, required for working memory (Cardin et al. 2009; Howard et al. 2003). The presence of high-conductance, rapidly gating glutamatergic receptors is needed for neural oscillations. NPTXs regulate circuit rhythmogenesis and integration by controlling expression and synaptic localization of AMPAR and coordination of excitatory synapses maturation onto PV interneurons (O’Brien et al. 1999; Pelkey et al. 2015). NPTX2 KO mice had an overall reduction of pyramidal neuron excitatory drive onto PV interneurons ( $\mathrm{Gu}$ et al. 2013). In addition,

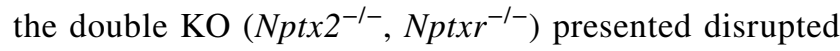
gamma oscillations and reduction of feedforward inhibition as a result of the reduction of one of the subunits of the AMPAR (Pelkey et al. 2015). The dense perineuronal net (proteoglycan network structure on the cell surface), characteristic of PV interneurons (Carceller et al. 2020; Härtig et al. 1999), is required to stabilise NPTX2 in the synaptic cleft at these synapses (Chang et al. 2010).

NPTXs contribute to various forms of synaptic plasticity. They are not exclusively present in PV interneuron synapses in the hippocampus, as they also regulate early synaptic refinements in retinal ganglion cell projections to dorsal lateral geniculate nucleus (Bjartmar et al. 2006). Moreover, they modulate LTD in synapses formed in hippocampus (Schaffer collateral-CA1 synapses), and cerebellum (Purkinje cells) (Cho et al. 2008). In vitro studies revealed that, in response to the activation of group 1 metabotropic receptor (mGluR $1 / 5)$, the metalloprotease tumour necrosis factor-alpha converting enzyme (TACE)-implicated in shedding of proteins (Black 2002)—cleaves NPTXR, releasing it from its $\mathrm{N}$-terminal transmembrane domain. Cleaved NPTXR is enabled to form membrane clusters with NPTX2 and is rapidly internalised and colocalizes with AMPAR in post-synaptic endosomes at synapses in the brain (Fig. 3a-4). 
This mechanism is necessary for LTD in hippocampus and cerebellum (Cho et al. 2008). A potential role of NPTXR as universal organizer of both excitatory and inhibitory synapses was observed in in vitro studies (Lee et al. 2017). However, the role of NPTXs in inhibitory synapses is less explored.

In summary, NPTXs are a family of proteins involved in homeostatic synaptic function and plasticity by recruiting post-synaptic receptors into synapses. Recent findings suggested an opposite regulation of the two soluble NPTXs, NPTX1 and NPTX2, by neuronal activity. NPTX1 is evoked during low neuronal activity and negatively regulates synaptic plasticity at excitatory synapses (DeGregorio-Rocasolano et al. 2001; Figueiro-Silva et al. 2015). Moreover, it participates in synaptic pruning by activation of the classical complement cascade (Kovács et al. 2020) (Fig. 3a-5) and may act as a sensor of harmful stimuli, targeting affected neurons to apoptotic cell death (Clayton et al. 2012; Rahim et al. 2013). In contrast, NPTX2 is activated in response to high neuronal activity and promotes synaptic plasticity at excitatory synapses (Tsui et al. 1996). This opposite role could act as a feedback mechanism to ensure homeostatic synaptic plasticity and precisely regulate the excitatory drive onto PV interneurons. In addition, NPTX heterocomplex play a dual role in synapse formation and depression. During synapse formation, NPTXs may capture and cluster AMPAR in the post-synaptic terminal; whereas during synapse depression, the complex is released from the membrane and captures AMPAR in post-synaptic endosomes. Early in development and in emerging synapses, NPTXs participate in synapse formation by clustering of AMPAR; while in mature synapses or chronic stimulation, they regulate LTD (Cho et al. 2008; O'Brien et al. 1999). This bidirectional mechanism is crucial to provide long-term plasticity to the involved networks.

\section{Neuronal pentraxins in synaptic dysfunction and neurodegeneration: a proposed mechanism}

Synaptic dysfunction and loss might be one of the earliest pathological mechanisms in the course of neurodegeneration (Gong and Lippa 2010; Janezic et al. 2013; Lui et al. 2016; Marttinen et al. 2015; Masliah et al. 2001; Selkoe 2002). The disruption of the protein network at the post-synaptic terminal is crucial for homeostatic synaptic plasticity (Gong and Lippa 2010). In particular, the deregulation of AMPA and/or NMDA receptors in inhibitory interneurons and the dysregulation of E/I balance could be responsible for the cognitive and behavioural abnormalities characteristic of a range of neurodegenerative and psychiatric disorders (Belforte et al. 2010; Bozzi et al. 2018; Caputi et al. 2012; Foss-Feig et al.
2017; Fuchs et al. 2007; Korotkova et al. 2010; Lewis et al. 2005; Maheshwari et al. 2013; Nelson and Valakh 2015; Palop and Mucke 2016; Xu et al. 2020). Moreover, complement-mediated synaptic pruning is essential for the normal function of the CNS, and it is hypothesised that alterations in this system contribute to excess synaptic loss and cognitive impairment in neurodegenerative disorders (Tenner et al. 2018). NPTXs could be involved in some of these pathogenic processes, given their role in AMPAR recruitment, modulation of excitatory synaptic drive and synaptic pruning. Consequently, targeting these proteins may be an effective strategy for the treatment of cognitive impairments.

Changes in the synthesis and/or secretion into the synaptic cleft of NPTX1 and NPTX2 could result in the impairment of their mode of action. If the role of astrocytes in NPTX1 release into the synaptic cleft is confirmed (FarhyTselnicker et al. 2017), the perturbation of normal astrocytic functions-common feature of various neurodegenerative disorders (Phatnani and Maniatis 2015) — could harm the physiological function of NPTXs (Fig. 3b-1). The reduced BDNF levels described in several neurodegenerative disorders could lead to a diminished NPTX2 synthesis, as BNDF is one of the main regulators of NPTX2 (Lima Giacobbo et al. 2019; Mariga et al. 2015) (Fig. 3b-2). According to the level of neuronal activity, NPTXs modulate synaptic plasticity through structural changes in the post-synaptic membrane. Deregulation of neuronal activity could explain changes in NPTXs and drive neurogenerative processes (Xiao et al. 2017). Under low neuronal activity, NPTX1 contributes to neuronal death and neurodegeneration. Under those circumstances, NPTX1 is guided to the mitochondria, where it induces BAX-dependent apoptosis, allowing the release of pro-apoptotic factors (Clayton et al. 2012). Moreover, intracellular NPTX1 impairs mitochondrial translocation into the synapses-required due to the high energy demand-by reduction of anterograde trafficking (Clayton et al. 2012) (Fig. 3b-3). On the other hand, NPTX2 was originally described as an IEG induced by seizures and stroke in the rat hippocampus; mechanisms that involved an excess of glutamate in the synaptic cleft (Schwarz et al. 2002; Tsui et al. 1996). Excess of glutamate may lead to an activation of mGluR $1 / 5$ and the consequent TACE cleavage of NPTXR. The internalisation of AMPAR receptors upon TACE action (Cho et al. 2008) may serve as a protective mechanism against the excess of glutamate (Schwarz et al. 2002). Consequently, an impairment of this mechanism could contribute to the excitotoxicity observed in neurodegenerative disorders (Dong et al. 2009) (Fig. 3b-4). The recently described role of NPTX1 in synaptic pruning, by activation of the complement-microglia axis, could be intensified upon neurodegeneration (Kovács et al. 2020) (Fig. 3b5). In summary, the deregulation of NPTXs expression levels, together with an imbalance in $\mathrm{E} / \mathrm{I}$ and the alteration in 
their apoptotic roles, could explain the changes in NPTXs expression and their concentration in CSF and brain tissue in neurodegeneration. However, it raises the question of whether NPTXs actively contribute to neurodegeneration, or whether the deregulation of these proteins is a consequence of the synaptic damage.

\section{Neuronal pentraxins in neurodegenerative, psychiatric and other disorders of the CNS}

\section{Measurements of neuronal pentraxins in biological fluids}

Measurements of NPTXs are mainly performed in CSF due to the insufficient assay sensitivity for a reliable quantification in blood samples. NPTXs levels can be quantified in CSF by means of mass spectrometry, enzyme-linked immunosorbent assay (ELISA) and Western Blot (WB) (Table 2). In comparison to those in other biological fluids, measurements of biomarkers in CSF offer several advantages. CSF is in direct contact with the brain, reflecting the changes occurring in this organ. Moreover, the dynamic range of CSF proteins is less variable, and CSF contains less high-abundant proteins that complicate the detection of low-expression proteins (Blennow et al. 2010). Additionally, the high expression of NPTXs in the brain compared with other body compartments reduces the risk of high peripheral NPTXs levels in the CSF. However, given that lumbar puncture is an invasive procedure, the need of CSF samples hinders the accessibility to longitudinal studies and the possibility to drive further conclusions regarding NPTXs potential as a disease progression marker. Accordingly, sensitive assays for reliable quantification in blood are needed. A study performed using WB was able to detect NPTXR in serum, and the values described the same trend as those obtained from CSF samples (Yin et al. 2009). This is reinforced by the correlation found between brain and plasma NPTX1 concentrations in transgenic AD mice (Ma et al. 2018). Hybrid immunoaffinity-mass spectrometry techniques have revealed the presence of synaptic proteins in blood (Kvartsberg et al. 2015; Oeckl et al. 2020), manifesting that NPTXs measurement in serum may be feasible in the future. However, the expression of some NPTX proteins in peripheral organs must be taken into consideration, as it could mask the pathological CSF findings in blood. The study of neuronal exosomes is a new promising research field to detect brain biomarkers in blood. Neuronal exosomes are released by neurons and carry cargo from their cells of origin. Due to their inherent capability to cross the blood-brain barrier, they are detectable in the blood (Song et al. 2020). A study on plasma neuronal exosomes of patients with AD dementia revealed declined levels of NPTX2 compared with matched controls. Similarly, its respective post-synaptic partner GluA4 already decreased in cognitively intact $\mathrm{AD}$ patients and further declined with disease progression, correlating with cognitive loss (Goetzl et al. 2018). However, the suitability of this method to specifically isolate plasma neuronal exosomes needs to be better clarified (Norman et al. 2021). In conclusion, novel, highly sensitive assays have to be established to further assess the potential of NPTXs as blood biomarkers in neurodegenerative disorders.

\section{Alzheimer's disease}

$\mathrm{AD}$ is the most common type of dementia. It is pathologically characterised by the presence of extracellular plaques of amyloid $\beta(\mathrm{A} \beta)$, intracellular neurofibrillary tangles of tau protein and brain atrophy caused by neuronal loss, mainly in the entorhinal cortex, the hippocampus, the neocortex and the nucleus basalis (Henstridge et al. 2019). To date, CSF $\mathrm{A} \beta_{42}$, total tau and $\mathrm{p}$-tau ${ }_{181}$ are the best characterised diagnostic fluid biomarkers in $\mathrm{AD}$, reflecting the core pathologies described above (Blennow and Zetterberg 2018). However, there is a need for biomarkers that specifically address other pathological features of $\mathrm{AD}$ such as synaptic degeneration, which might have a better prognostic value and be better to evaluate the efficacy of new therapies. NPTXs may be potential candidate biomarkers in AD due to their expression in neocortex and hippocampus (Uhlén et al. 2015; Xu et al. 2003), areas that are largely affected by synaptic dysfunction and loss in AD (Davies et al. 1987; DeKosky and Scheff 1990; Reddy et al. 2005; Scheff et al. 2007). NPTXs might also underly some of the neurotoxic effects of $A \beta$ aggregation (Abad et al. 2006), which is known to affect excitatory synaptic transmission and neuronal activity, mechanisms that precede neurite degeneration and neuronal death (Kamenetz et al. 2003; Walsh and Selkoe 2004) and subsequent cognitive failure (Driscoll and Troncoso 2011; Jack and Holtzman 2013). Accordingly, NPTXs were found to be the only markers that correlate with $A \beta_{42}$ in AD (Nilsson et al. 2021). This could be due to a reduction in AMPAR (Rui et al. 2010; Xiao et al. 2017), glutamatergic receptors clustered and stabilised by NPTXs (O'Brien et al. 1999), thus resulting in a disruption of the pyramidal neuron-PV interneuron circuit (Xiao et al. 2017). PV interneurons, where NPTXs play a crucial role (Chang et al. 2010), are cells highly vulnerable in the AD brain (Brady and Mufson 1997; Takahashi et al. 2010). In a mouse model of $A \beta$ amyloidosis, deficits in these interneurons contributed to abnormalities in oscillatory rhythms (especially in the gamma spectrum), network synchrony, and cognition (Verret et al. 2012). Optogenetically activated PV interneurons at gamma oscillations reduced $A \beta_{40}$ and $A \beta_{42}$ isoforms (Iaccarino et al. 2016). Last, the perineuronal net required for NPTX2 localization in the synaptic cleft (Chang et al. 2010) is affected in $\mathrm{AD}$ and might lead to the deregulation of this protein (Baig et al. 2005). 
Table 2 Summary table of the studies assessing NPTXs CSF in Alzheimer's disease (AD) and frontotemporal lobar degeneration (FTLD) included in the present review

\begin{tabular}{|c|c|c|c|c|c|c|c|}
\hline & Study & Methodology & Study design & Cohort & Summary of findin & & \\
\hline & & & & & NPTX1 & NPTX2 & NPTXR \\
\hline AD & $\begin{array}{l}\text { Brinkmalm et al. } \\
\text { (2018) }\end{array}$ & $\begin{array}{l}\text { Mass spectrom- } \\
\text { etry }\end{array}$ & Cross-sectional & $15 \mathrm{CTL}, 10 \mathrm{AD}$ & $\downarrow$ AD vs CTL & & \\
\hline & Xiao et al. (2017) & WB and ELISA & Cross-sectional & $36 \mathrm{CTL}, 30 \mathrm{AD}$ & $\downarrow$ AD vs CTL & $\downarrow$ AD vs CTL & $\downarrow \mathrm{AD}$ vs CTL \\
\hline & Duits et al. (2018) & $\begin{array}{l}\text { Mass spectrom- } \\
\text { etry }\end{array}$ & Longitudinal & $\begin{array}{l}40 \text { CTL, } 40 \text { AD } \\
\text { dementia, } 40 \\
\text { MCI } \\
\text { (13 sMCI, } 14 \\
\text { MCI-AD) }\end{array}$ & $\begin{array}{l}\uparrow \mathrm{MCI} \text { vs CTL } \\
\downarrow \mathrm{AD} \text { dementia vs } \\
\mathrm{MCI}^{\mathrm{a}}\end{array}$ & & \\
\hline & $\begin{array}{l}\text { Galasko et al. } \\
\text { (2019) }\end{array}$ & ELISA & Cross-sectional & $\begin{array}{l}90 \text { CTL, } 57 \text { MCI, } \\
46 \text { AD }\end{array}$ & & $\begin{array}{l}\downarrow \text { MCI vs CTL } \\
\downarrow \text { AD vs CTL }\end{array}$ & \\
\hline & $\begin{array}{l}\text { Nilsson et al. } \\
\text { (2021) }\end{array}$ & $\begin{array}{l}\text { Mass spectrom- } \\
\text { etry }\end{array}$ & Cross-sectional & $\begin{array}{l}\text { Pilot study: } 20 \\
\text { CTL, } 20 \text { AD } \\
\text { Validation cohort: } \\
20 \text { CTL, } 32 \text { AD }\end{array}$ & $\approx \mathrm{AD}$ vs $\mathrm{CTL}$ & $\downarrow \mathrm{AD}$ vs $\mathrm{CTL}^{\mathrm{b}}$ & $\downarrow \mathrm{AD}$ vs $\mathrm{CTL}^{\mathrm{b}}$ \\
\hline & $\begin{array}{l}\text { Soldan et al. } \\
\text { (2019) }\end{array}$ & ELISA & Cross-sectional & 130 CTL, 19 MCI & & $\downarrow$ MCI vs CTL & \\
\hline & $\begin{array}{l}\text { Libiger et al. } \\
\text { (2021) }\end{array}$ & $\begin{array}{l}\text { Mass spectrom- } \\
\text { etry }\end{array}$ & Longitudinal & 76 CTL, $111 \mathrm{MCI}$ & & $\begin{array}{l}\downarrow 10 \% \text { in } 5 \text { years } \\
\text { in } \mathrm{AD}\end{array}$ & \\
\hline & $\begin{array}{l}\text { Hendrickson et al. } \\
\text { (2015) }\end{array}$ & $\begin{array}{l}\text { Mass spectrom- } \\
\text { etry }\end{array}$ & Longitudinal & $\begin{array}{l}30 \text { CTL, } 30 \\
\text { AD (severely } \\
\text { impaired) }\end{array}$ & & & $\begin{array}{l}\downarrow \text { AD vs CTL } \\
(\downarrow 6.9 \% / \text { year })\end{array}$ \\
\hline & Lim et al. (2020) & ELISA & Longitudinal & $\begin{array}{l}46 \text { CTL, } 28 \mathrm{MCI} \text {, } \\
27 \mathrm{MCI}-\mathrm{AD}, \\
28 \mathrm{AD}\end{array}$ & & & $\begin{array}{l}\downarrow \text { AD vs CTL } \\
(\downarrow 6.7 \% / \text { year })\end{array}$ \\
\hline & $\begin{array}{l}\text { Llano et al. } \\
\text { (2017) }\end{array}$ & $\begin{array}{l}\text { Mass spectrom- } \\
\text { etry }\end{array}$ & Cross-sectional & $\begin{array}{l}86 \text { CTL, } 135 \\
\text { MCI, } 66 \text { AD }\end{array}$ & & & $\begin{array}{l}\uparrow \text { MCI vs CTL } \\
\downarrow \text { AD dementia vs } \\
\text { MCI }\end{array}$ \\
\hline & $\begin{array}{l}\text { Wildsmith et al. } \\
\text { (2014) }\end{array}$ & $\begin{array}{l}\text { Mass spectrom- } \\
\text { etry }\end{array}$ & Longitudinal & $\begin{array}{l}10 \mathrm{CTL}, 5 \mathrm{MCI}, \\
45 \mathrm{AD}\end{array}$ & & & $\downarrow 10 \% /$ year in $\mathrm{AD}$ \\
\hline & $\begin{array}{l}\text { Begcevic et al. } \\
\text { (2018) }\end{array}$ & $\begin{array}{l}\text { Mass spectrom- } \\
\text { etry and ELISA }\end{array}$ & Cross-sectional & $\begin{array}{l}\text { Cohort MS: } 8 \\
\text { MCI, } 11 \text { mild } \\
\text { AD, } 24 \text { moder- } \\
\text { ate AD, } 15 \\
\text { severe AD } \\
\text { Cohort ELISA: } \\
6 \mathrm{MCI}, 8 \text { mild } \\
\text { AD, } 16 \text { moder- } \\
\text { ate AD, } 13 \\
\text { severe AD }\end{array}$ & & & $\begin{array}{c}\text { Progressive } \downarrow \text { with } \\
\text { disease severity }\end{array}$ \\
\hline & Lim et al. (2019) & ELISA & Cross-sectional & $\begin{array}{l}14 \mathrm{MCI}, 21 \text { mild } \\
\mathrm{AD}, 43 \text { moder- } \\
\text { ate } \mathrm{AD}, 30 \\
\text { severe } \mathrm{AD}\end{array}$ & & & $\begin{array}{c}\text { Progressive } \downarrow \text { with } \\
\text { disease severity }\end{array}$ \\
\hline & Yin et al. (2009) & WB & Cross-sectional & 4 CTL, 5 AD & & & $\uparrow A D$ vs CTL \\
\hline
\end{tabular}


Table 2 (continued)

\begin{tabular}{|c|c|c|c|c|c|c|c|}
\hline & \multirow[t]{2}{*}{ Study } & \multirow[t]{2}{*}{ Methodology } & \multirow[t]{2}{*}{ Study design } & \multirow[t]{2}{*}{ Cohort } & \multicolumn{3}{|c|}{ Summary of findings } \\
\hline & & & & & NPTX1 & NPTX2 & NPTXR \\
\hline \multirow[t]{4}{*}{ FTLD } & $\begin{array}{l}\text { Van der Ende } \\
\text { et al. } 2019\end{array}$ & $\begin{array}{l}\text { Mass spectrom- } \\
\text { etry }\end{array}$ & Cross-sectional & $\begin{array}{l}52 \mathrm{NC}, 59 \mathrm{PMC} \\
99 \mathrm{SMC}\end{array}$ & & & $\begin{array}{l}\downarrow \text { FTLD SMC vs } \\
\text { NC }\end{array}$ \\
\hline & $\begin{array}{l}\text { Van der Ende } \\
\text { et al. (2020) }\end{array}$ & ELISA and WB & $\begin{array}{l}\text { Cross-sec- } \\
\text { tional/ Longi- } \\
\text { tudinal }\end{array}$ & $\begin{array}{l}70 \text { NC, } 106 \text { PMC, } \\
54 \text { SMC }\end{array}$ & $\begin{array}{l}\downarrow \text { FTLD SMC vs } \\
\text { PMC and NC }\end{array}$ & $\begin{array}{l}\downarrow \text { FTLD SMC vs } \\
\text { PMC and NC. } \\
\text { Progressive } \downarrow \\
\text { in SMC and in } \\
\text { PMC over the } \\
\text { age of } 50 \text { years }\end{array}$ & $\begin{array}{l}\downarrow \text { FTLD SMC vs } \\
\text { PMC and NC }\end{array}$ \\
\hline & $\begin{array}{l}\text { Barschke et al. } \\
\text { (2020) }\end{array}$ & $\begin{array}{l}\text { Mass spectrom- } \\
\text { etry }\end{array}$ & Cross-sectional & $\begin{array}{l}28 \text { asymptomatic } \\
\text { C9orf72 MC, } \\
18 \text { c9FTD, } 28 \\
\text { c9ALS }\end{array}$ & & & $\begin{array}{l}\downarrow \text { c9FTD vs } \\
\text { asymptomatic } \\
\text { C9orf72 MC }\end{array}$ \\
\hline & $\begin{array}{l}\text { Remnestål et al. } \\
\text { (2020) }\end{array}$ & $\begin{array}{l}\text { Antibody suspen- } \\
\text { sion bead array }\end{array}$ & Cross-sectional & $\begin{array}{l}\text { Pilot study: } 8 \text { NC, } \\
16 \text { PMC, } 29 \\
\text { FTLD } \\
\text { Validation cohort: } \\
18 \text { CTL, } 79 \text { AD, } \\
13 \text { FTLD }\end{array}$ & & & $\begin{array}{l}\downarrow \text { FTLD vs CTL } \\
\text { (NC, PMC) }\end{array}$ \\
\hline
\end{tabular}

\footnotetext{
a NPTX1 was elevated in the patients with MCI-AD compared with sMCI. AD patients had lower, but not statistically significant, NPTX1 compared with CTLs. ${ }^{b}$ No differences found in the pilot study (biochemically defined), only in the validation cohort (clinically diagnosed subjects). CTL, control; AD, Alzheimer's disease; MCI, mild cognitive impairment; sMCI, stable MCI; MCI-AD, MCI patients who progressed to AD; FTLD, frontotemporal lobar degeneration; NC, non-carriers; MC, mutation carriers; PMC, pre-symptomatic mutation carriers; SMC, symptomatic mutation carriers; c9FTD, FTLD cases with hexanucleotide repeat expansion in the C9orf72 gene; c9ALS, ALS cases with hexanucleotide repeat expansion in the $\mathrm{C} 9$ orf72 gene
}

NPTX1 was upregulated in the brain of patients with sporadic late-onset $\mathrm{AD}$, and located with $\mathrm{A} \beta$ and tau deposits in dystrophic neurites (Abad et al. 2006). By contrast, another study found no changes of NPTX1 in neither of the cortical regions analysed (hippocampus not included) (Xiao et al. 2017). NPTX1 may play a key role in synaptic loss, neurite damage and neuronal apoptosis, mechanisms evoked by A $\beta$ (Abad et al. 2006). Several hypotheses could explain the role of NPTX1 in neuronal toxicity in AD. First, the translocation of NPTX1 from the synaptic cleft into the mitochondria could reduce the ability of the NPTX complex to cluster AMPARs and will activate BAX-dependent apoptosis (Clayton et al. 2012). Second, the increase in NPTX1 may promote the excessive synaptic loss in AD (Terry et al. 1991), due to an excess of the complement-mediated synaptic pruning (Kovács et al. 2020). Last, the interaction of NPTX1 with an intracellular form of NPTXR, capable of remodelling chromatin, may disrupt the association of NPTXR with the receptor protein tyrosine phosphatase O, required for neurite outgrowth (hypothesis under investigation) (Abad et al. 2006; Chen and Bixby 2005). Based on these data, reduction of NPTX1 expression could be a drug target to prevent synaptic dysfunction and loss in neurodegeneration (Figueiro-Silva et al. 2015). Several studies conducted in human CSF from AD patients reported a reduction of NPTX1 levels in AD patients compared with healthy controls (Brinkmalm et al. 2018; Xiao et al. 2017). On the other hand, NPTX1 levels were found to be elevated in patients with mild cognitive impairment (MCI) progressing to $\mathrm{AD}$ (Duits et al. 2018). The method of measurement (mass spectrometry vs WB) together with the small sample size could account for the discrepancy in the results. Furthermore, we could also speculate on an increase of CSF NPTX1 levels in the earliest stages of the disease, followed by a drop in the dementia phase (Table 2).

CSF NPTX2 levels assessed by WB, in-house ELISA and mass spectrometry were decreased in both sporadic and genetic forms of $\mathrm{MCI}$ and $\mathrm{AD}$ dementia in comparison with cognitive healthy controls (Belbin et al. 2020; Galasko et al. 2019; Nilsson et al. 2021; Soldan et al. 2019; Xiao et al. 2017). A mass spectrometry-based approach revealed NPTX2 as one of the best markers to differentiate between progressive and non-progressive MCI (Spellman et al. 2015). The receiver operating characteristic (ROC) analysis concluded a similar test performance to distinguish $\mathrm{AD}$ from controls than that of the classical AD biomarkers (Xiao et al. 2017). The ratio tau or p-tau with NPTX2 reported the best performance to discriminate AD vs controls (Galasko et al. 2019; Xiao et al. 2017). NPTX2 was also decreased in post-mortem cortex from AD patients (hippocampus not analysed) (Xiao et al. 2017). The subunit of AMPAR, GluA4, was also reduced in this study (both in the precuneus 
and medial frontal gyri) and correlated with NPTX2 in both control and AD group (Xiao et al. 2017). GluA4 is selectively enriched in PV interneurons in human cortex and is regulated by NPTXs (Sia et al. 2007; Xiao et al. 2017). Consequently, the reduction of NPTX 2 could be linked to the disruption of pyramidal neuron-PV interneuron microcircuit, contributing to cognitive failure in AD (Xiao et al. 2017). This was further sustained by studies that found NPTX2 correlating with medial temporal atrophy, hippocampal volume and cognitive impairment (Nilsson et al. 2021; Swanson et al. 2016; Xiao et al. 2017). In addition, new evidence suggested NPTX2 as a strong prognostic biomarker candidate of cognitive decline (Libiger et al. 2021). Therefore, NPTX2 could be an accurate predictor of AD-outcome helping to track cognitive failure in AD (Galasko et al. 2019) (Table 2).

CSF NPTXR was identified by discovery proteomics to be associated with AD in several studies (Ringman et al. 2012; Wildsmith et al. 2014). CSF NPTXR levels, both the full length protein and the peptides resulting from TACE cleavage, were reduced in $\mathrm{AD}$ in comparison with controls (Xiao et al. 2017). Similar to NPTX1, NPTXR levels in CSF were slightly higher in MCI than in controls and decreased progressively with disease severity by an average of 7-10\% per year (Hendrickson et al. 2015; Lim et al. 2020; Llano et al. 2017; Wildsmith et al. 2014). Accordingly, CSF NPTXR can discriminate between advanced AD stages and MCI (Area under the curve $=0.799$ ) (Begcevic et al. 2018; Lim et al. 2019). These data were also consistent with a study in pre-symptomatic mutation carriers that reported a trend towards elevated NPTXR and NPTX2 CSF levels in comparison with non-carriers (Ringman et al. 2012). Another study documented higher levels of NPTXR in CSF of $\mathrm{AD}$ patients in comparison with controls. However, the severity of the cognitive impairment and the disease stage were not addressed (Yin et al. 2009). This, together with the method of measurement and the small sample size, could explain the differences observed. In summary, NPTXR could be a new biomarker of AD progression and help to assess therapy performance (Begcevic et al. 2018; Lim et al. 2020, 2019; Wildsmith et al. 2014) (Table 2).

Overall, these results reflect an increase of NPTX1 and NPTXR in pre-symptomatic stages of genetic AD, MCI and early stages of $\mathrm{AD}$, whereas they decrease in later dementia stages (Duits et al. 2018; Lim et al. 2020; Llano et al. 2017; Ringman et al. 2012; Wildsmith et al. 2014). This is consistent with other studies that have suggested a transient peak in biomarker levels (neurosecretory protein VGF, neurexin, cystatin $\mathrm{C}$, functional magnetic resonance imaging (MRI)) in the early stages of the disease (Dickerson et al. 2005; Duits et al. 2018; McDade et al. 2018). In addition, the behaviour of NPTX1 and NPTXR could be explained by the biphasic activity of the glutamatergic system in the hippocampus, with increased activity in MCI, followed by a decline during the dementia stage (Findley et al. 2019). By contrast, NPTX2 seems to be downregulated in all symptomatic stages of the disease, suggesting a different pathogenic behaviour of this protein in AD (Galasko et al. 2019; Nilsson et al. 2021; Soldan et al. 2019; Xiao et al. 2017). Taken together, NPTXs may be novel markers for AD, anticipating disease progression and predicting cognitive failure.

\section{Frontotemporal lobar degeneration}

FTLD is a group of progressive neurodegenerative disorders. It is characterised by a selective neuronal loss in the frontal and temporal lobes, leading to deficits in behaviour, executive function and/or language (Bright et al. 2019). The disease can be misdiagnosed as a psychiatric disorder due to the prominent behavioural symptoms (Bang et al. 2015; Rascovsky et al. 2011). To date, specific fluid diagnostic biomarkers are missing (Swift et al. 2021). Increasing evidence suggests synaptic degeneration to be one of the first pathological mechanisms in FTLD (Gong and Lippa 2010; Ling 2018; Lui et al. 2016; Marttinen et al. 2015). Therefore, synaptic biomarkers might contribute to early diagnosis and evaluation of disease progression. The impairment in hippocampal GABAergic function, the alteration in AMPAR and the reduction in the neurotransmitter glutamate in the frontal cortex (Gascon et al. 2014; Levenga et al. 2013; Murley et al. 2020; Procter et al. 1999) may lead to some of the neuropathophysiological characteristics of FTLD. Hence, NPTXs may be novel, possible candidate biomarkers given their role as regulators of AMPAR in PV GABAergic interneurons (Chang et al. 2010; O'Brien et al. 1999).

Recent studies have evaluated CSF NPTXs as novel biomarkers of genetic FTLD (Barschke et al. 2020; Remnestål et al. 2020; van der Ende et al. 2020, 2019). Data obtained with in-house ELISA exhibited lower CSF NPTX2 concentration in symptomatic mutations carriers than in presymptomatic and non-carriers. WB and mass spectrometry analysis of NPTX1 and NPTXR yielded similar results (van der Ende et al. 2020, 2019). NPTXs levels did not differ depending on genetic cause. The diagnostic accuracy of NPTX2 (Area under the curve: 0.71), to distinguish symptomatic mutation carriers from non-carriers, was comparable with that of neurogranin, one of the most accepted synaptic biomarkers (van der Ende et al. 2020). Among mutation carriers, NPTX 2 correlated with cognitive impairment, grey matter volume of the whole brain as well as of frontal, parietal and temporal lobes and insula. A preliminary longitudinal analysis of 13 patients revealed a decline over time in NPTX2 in symptomatic mutation carriers and in presymptomatic mutations carriers over the age of 50 years (van der Ende et al. 2020). Furthermore, deep proteomic study by mass spectrometry revealed decreased NPTXR CSF levels in c9FTD compared with asymptomatic mutation carriers. 
c9FTD refers to the most common genetic form of FTLD that is caused by the hexanucleotide repeat expansion in the C9orf72 gene. Even though C9orf72 is also the cause of most of the genetic amyotrophic lateral sclerosis (c9ALS) cases, the decrease in NPTXR was specific to c9FTD (Barschke et al. 2020). To date, one study has reported data in sporadic FTLD by antibody suspension bead array. This study revealed decreased levels of NPTXR in CSF of FTLD patients (both sporadic and genetic forms) in comparison with non-carriers and pre-symptomatic mutation carriers. No differences in NPTXR CSF levels were detected between AD and FTLD (Remnestål et al. 2020) (Table 2).

In summary, these findings suggest an overall reduction of NPTXs in genetic and sporadic FTLD. In particular, NPTX2 decreases paralleling disease progression and may reflect an association between synaptic disruption and cognitive impairment. Moreover, NPTXR illustrates a different role of synaptic dysfunction in c9FTD and c9ALS, and their potential as differential diagnosis marker may be worth studying. Thus, the previous studies reinforce the potential application of NPTXs as an early disease and prognostic marker for FTLD, mainly in the genetic forms (van der Ende et al. 2020).

\section{Synucleinopathies: Parkinson's disease and dementia with Lewy bodies}

PD and dementia with Lewy bodies (DLB) are proteinopathies characterised by aggregation of the pre-synaptic protein, $\alpha$-synuclein (Camporesi et al. 2020; Outeiro et al. 2019; Wong and Krainc 2017). Synaptic dysfunction contributes to disease pathogenesis in PD (Nguyen et al. 2019) and may be linked to cognitive and motor dysfunction (Bereczki et al. 2017; Moran et al. 2008). NPTXs might be interesting biomarker candidates due to the high susceptibility of dopaminergic neurons in vitro to excitotoxicity and non-apoptotic cell death induced by the activation of AMPAR (regulated by NPTXs) (Dorsey et al. 2006). Moreover, NPTXs are expressed in hypothalamic nerve cells, which may be implicated in the sleep disturbances found in PD patients (Crocker et al. 2005; Thannickal et al. 2007). A whole genome expression profiling revealed NPTX2 to be the most highly upregulated gene in the substantia nigra of sporadic PD patients (Moran et al. 2008). Additionally, it accumulated in Lewy bodies and neurites in substantia nigra and cerebral cortex (Moran et al. 2008). NPTX2 may be implicated in the motor and cognitive impairment caused by dopaminergic nerve cell degeneration in the midbrain and synaptic alteration in the cerebral cortex, respectively (Lang et al. 2020; Moran et al. 2008). In a mouse model of PD, NPTX2 was overexpressed in the striatum after L-DOPA treatment and contributed to the development of L-DOPA-induced dyskinesia (Charbonnier-Beaupel et al. 2015). Synaptic dysfunction and loss, mainly localised in the primary visual cortex, may also contribute to DLB (Khundakar et al. 2016; MukaetovaLadinska et al. 2013). This could be due to an impairment of the GABAergic transmission and a possible interneuron dysfunction in this region (Khundakar et al. 2016), where NPTXs participate in synaptic refinement (Bjartmar et al. 2006). NPTX2 CSF levels were lower in patients with DLB than in cognitive healthy controls (Boiten et al. 2020). Additionally, these values correlated with cognitive function in the visual spatial domain (Boiten et al. 2020). These results suggested an impairment of the principal neuron-interneuron microcircuit in the primary visual cortex in DLB patients, reflected by a decline in CSF NPTX2 levels (Boiten et al. 2020). Further to this, NPTXR and NPTX1 were decreased in atypical parkinsonian disorders (progressive supranuclear palsy, multiple system atrophy, corticobasal degeneration) in comparison with controls (Magdalinou et al. 2017). To summarise, the results stated above support NPTX2 as a novel candidate protein in $\alpha$-synuclein pathology.

\section{Psychiatric disorders}

Dysfunction and/or deficient inhibitory output from PV interneurons may be a common mechanism of multiple psychiatric disorders, such as schizophrenia (SCZ) (Lewis et al. 2005), autism spectrum disorders (ASD) (Gao and Penzes 2015) and bipolar disorder (BD) (Ruden et al. 2021). The disruption of the perineuronal net, required for NPTX2 localization in the synaptic cleft (Chang et al. 2010) and disrupted in SCZ, might be contributing to the previously described GABAergic dysfunction (Berretta et al. 2015). In vivo studies suggested improvements in cognition and memory by activation of PV interneurons in the medial prefrontal cortex, restoring GABAergic signalling and E/I balance (Ferguson and Gao 2018). In addition, an imbalance in synaptic connectivity during perinatal and adolescence periods is being hypothesized as a possible mechanism of SCZ and ASD (Gilbert and Man 2017; McGlashan and Hoffman 2000). Hence, we speculate an involvement of NPTXs in the pathogenic mechanism of psychiatric disorders given their role in synaptogenesis, synaptic pruning and in the regulation of the excitatory drive onto PV interneurons. Chromosomal breakpoint analysis in patients with BD suggested NPTX1 as a novel candidate gene for BD (Rajkumar et al. 2015). NPTX1 could contribute to BD pathology by deregulation of glutamatergic synaptic transmission (Eastwood and Harrison 2010).

\section{Other disorders of the CNS: epilepsy, stroke, neuroinflammatory diseases and brain tumours}

NPTXs have also been studied in other disorders affecting the CNS. NPTX2 was initially discovered to be released 
from the pre-synaptic terminal in response to seizures (O'Brien et al. 1999). In accordance with these results, Nptx 2 mRNA was enriched in the rat hippocampus after maximal electroconvulsive seizure (MECs) (Tsui et al. 1996). However, NPTX1 was constitutively expressed in the adult brain with levels unchanged after MECs (Xu et al. 2003). Aside from these initial discoveries, little research has focussed on the role of NPTXs in epileptic seizures. NPTXs could contribute to the long-term E/I imbalance characteristic of epilepsy by altering AMPAR neurotransmission (Bonansco and Fuenzalida 2016; Lopes et al. 2013). The role of NPTXs was also explored in ischaemic stroke. NPTX1 was induced after hypoxic-ischaemic neuronal injury and led to the release of cytochrome $\mathrm{C}$ and the activation of caspase-3 (Rahim et al. 2013). In in vitro conditions that mimic human strokes, the deletion of NPTX1 resulted in decreased neuronal death in comparison with wildtype neurons, potentially due to the reduced surface GluA1. This indicates a crucial role of NPTX1 in AMPAR clustering and suggests NPTX1 as a potential target to prevent the consequences of strokes (Al Rahim and Hossain 2013). Similarly, NPTX2 was upregulated in a rat model of cerebral ischaemia. This may promote AMPAR internalization, protecting against excitotoxicity (Schwarz et al. 2002). There is limited evidence to sustain the role of NPTXs in neuroinflammatory disorders. One study reported decreased CSF levels of NPTXR in multiple sclerosis compared with other neurological disorders (Kroksveen et al. 2012). Hence, future studies need to address the potential of these proteins as biomarkers of neuroinflammation. The involvement of NPTXs was broadly studied in brain cancer research (Bartolini et al. 2015; Huo et al. 2019; Wang et al. 2020). Notably, the involvement of these proteins in tumour development might be related to the role of AMPAR in tumours (Radin and Patel 2017; Wang et al. 2020), together with the inflammatory function of NPTXs. However, in-depth research is needed to determine their involvement in tumour progression.

\section{Correlation between NPTXs and other recognised markers of neurodegeneration}

Several studies addressed the correlation between NPTXs and already established biomarkers. NPTX2 exhibited a weak correlation with p-tau ${ }_{181}$ and total tau (Xiao et al. 2017). With total tau, the correlation was more robust in the late stages of $\mathrm{AD}$ (Galasko et al. 2019). On the other hand, the $\mathrm{A} \beta_{42}$ data is less consistent. Some authors described a weak correlation with $\mathrm{A} \beta_{42}$, mainly in MCI (Galasko et al. 2019; Nilsson et al. 2021), whereas others found no correlation (Xiao et al. 2017). NPTX1 and NPTXR did not correlate with $A \beta_{42}$, but did weakly correlate with total tau and p-tau ${ }_{181}$ (Xiao et al. 2017). Another study reported no correlation between NPTXR and core AD biomarkers, except in the control group (Lim et al. 2020). The authors suggested the biphasic behaviour of NPTXR in CSF could explain these results across the different stages of AD (Lim et al. 2020). NPTXs seemed to moderately correlate with many synaptic markers (e.g., $\beta$-synuclein, $\gamma$-synuclein, neurogranin, syntaxin, SNAP25) in the healthy control and the AD group. Intriguingly, they declined in AD patients, opposite to the other synaptic markers that primarily increased in CSF (Galasko et al. 2019; Nilsson et al. 2021). As for non-AD conditions, NPTX2 correlated with CSF levels of other synaptic proteins such as neurosecretory protein VGF and $\alpha$-synuclein in DLB (Boiten et al. 2020). Moreover, NPTX2 was inversely correlated with CSF neurofilament light concentrations - a marker of neuroaxonal damage and disease severity - in genetic forms of FTLD (van der Ende et al. 2020). Finally, CSF levels of the different NPTXs strongly correlated with each other in both AD and genetic FTLD, indicating an overall reduction of these proteins in CSF (Nilsson et al. 2021; van der Ende et al. 2020; Xiao et al. 2017).

\section{Discussion and conclusion}

The progressive synaptic impairment in neurodegenerative and other diseases of the CNS remains to be fully elucidated. However, emerging scientific literature supports its role during the first stages of neurodegeneration. More research needs to be conducted to reveal the pathological mechanisms that lead to synaptic degeneration and loss. Untangling the pathological changes occurring in the first steps of these diseases could provide critical information for early diagnosis and even help to identify novel therapeutic targets.

As synaptic proteins, NPTXs represent promising early disease and prognostic biomarker candidates for structural and functional synaptic impairment in neurodegenerative conditions. Unlike core biomarkers such as $\mathrm{A} \beta$ (Williams et al. 2011), CSF NPTXs levels correlated with cognitive scores in AD patients, even in the absence of brain pathology. Thus, they might be a good candidate biomarker for disease staging and cognitive prognosis (Galasko et al. 2019; Libiger et al. 2021; Nilsson et al. 2021; Swanson et al. 2016; Xiao et al. 2017). NPTXs also showed an added role when combined with core AD biomarkers in predicting the progression from $\mathrm{MCI}$ to $\mathrm{AD}$ dementia and in discriminating AD and healthy controls, e.g., NPTX2 in ratio with either total tau or p-tau (Galasko et al. 2019; Xiao et al. 2017). However, new studies addressing the value of CSF NPTXs in the differential diagnosis between $\mathrm{AD}$ and other neurodegenerative disorders are needed.

NPTXs may contribute to the cognitive decline in neurodegeneration and other diseases of the CNS by modifying the excitatory synaptic drive onto fast-spiking PV interneurons 
which leads to E/I imbalance. This might promote or accelerate disease progression by increasing the demand in other compensatory mechanisms (Hu et al. 2010; Shepherd et al. 2006; Xiao et al. 2017). In addition, NPTXs deregulation could lead to an imbalance in synaptogenesis/synaptic pruning (Kovács et al. 2020). The AD studies displayed in this review describe a tendency towards a transient increase in NPTXs during early stages of the disease, when the cognitive impairment is mild, followed by a progressive decrease paralleling disease severity. One potential explanation is the existence of a compensatory mechanism in the early stages of the synaptic damage, followed by a decrease in synaptic markers due to neuronal loss. In the pre-symptomatic stage, NPTXs may act as a resilience factor keeping the integrity of the synapses, as previously hypothesised (Xiao et al. 2017). When the disease progresses, the loss of NPTXs may contribute to the cognitive impairment. Another hypothesis is that the increased CSF synaptic protein concentration may be a consequence of the protein leakage into the interstitial fluid upon synaptic damage and early neuronal loss (Wellington et al. 2016); whereas in later stages, the aggregation with misfolded proteins in the tissue (Bereczki et al. 2017) and the confounded widespread neurodegeneration would explain the reduced CSF values. Moreover, the role of NPTX1 in neuronal cell death could also explain the increased levels of this protein in early stages of the disease. A validation of the results obtained in the FTLD cohort is required to confirm a similar behaviour of NPTXs in this pathology. The increased NPTX1 observed in brain tissue from $\mathrm{AD}$ patients may be due to the aggregation into neurite plaques. Taken together, the disease stage might affect the synaptic protein levels both in the brain and in CSF.

The application of NPTXs as fluid biomarkers in neurodegeneration requires to overcome some outstanding challenges. First, to unravel their signalling pathways, role in the disease and behaviour in the biofluids. This would help to clarify the sometimes-controversial levels of the different NPTXs in CSF and brain tissue. Second, to untangle the detailed expression pattern of these proteins in the different regions of the brain. Third, to standardise protocols regarding sample handling, methodology and analytical parameters to get reproducible data. Fourth, to get access to big cohorts with patients that have been well characterised clinically and to define a clear inclusion and exclusion criteria. This would allow further conclusions regarding the behaviour of these proteins during the course of the diseases. Fifth, to analyse the levels of CSF NPTXs across a broader range of diseases of the CNS, including both genetic and sporadic subtypes. Last, to address the potential of these proteins as markers of disease progression, moving from cross-sectional to longitudinal study designs. The latest improvements in high-resolution mass spectrometry, together with automated immunoassays and single molecule array (Simoa), may allow the development of more sensitive assays capable of measuring NPTXs and other synaptic markers both in CSF and blood. In addition, new studies are needed to determine the potential of plasma neuron-derived exosomes as a new approach to detect early biomarkers of neurodegeneration in blood samples (Song et al. 2020).

Additional questions remain to be addressed to understand the role of NPTXs in synaptic function and their potential as fluid biomarkers and drug targets. Is the deregulation of NPTXs one of the pathological mechanisms behind cognitive impairment in neurodegenerative and psychiatric disorders, or is it merely a consequence of the synaptic damage? Do NPTXs participate in the PV interneurons impairment observed in various diseases of the CNS? Considering the structural similarity between NPTXs and the classical pentraxins CRP and SAP, could these proteins play a complementary role in synaptic activity and neuroinflammation during blood-brain barrier breakdown (Cummings et al. 2017)? Could NPTXs participate in pathological neuroinflammation? Is their role as mediators of the complementdependent synaptic pruning, altered upon pathological conditions, explaining the excess of neuronal loss in neurodegenerative diseases? While NPTX2 promotes synaptic plasticity at excitatory synapses, NPTX1 is part of the mechanism of neuronal apoptosis and negatively regulates synaptic plasticity at excitatory synapses (DeGregorio-Rocasolano et al. 2001; Figueiro-Silva et al. 2015; Tsui et al. 1996). This "opposite" molecular mechanism could act as a homeostatic feedback and may have important implications in the role of NPTXs in neurodegenerative disorders. The synaptic changes occurring even a decade before clinical onset reflect the potential applicability of synaptic proteins as therapeutic targets (Ringman et al. 2012). Innovative molecular tools intended to restore the function of synaptic organizers, as NPTXs, could provide potential treatments to remodel impaired neuronal circuits in neurological disorders (Suzuki et al. 2020). Further studies are required to determine NPTXs potential as in vivo monitoring of synaptic dysfunction and drug targets.

In summary, excess synaptic loss and alteration of the post-synaptic terminal are common mechanisms of neurodegeneration. NPTXs may contribute or reflect the impairment in synaptic plasticity and/or loss by altering the normal integration of AMPAR in the post-synaptic terminal and disrupting the synaptogenesis/synaptic pruning balance. They are a promising candidate for early diagnosis and prognosis of cognitive decline and may provide crucial information to understand some of the pathological mechanisms behind many diseases of the CNS. However, the observed alteration in different disorders reflect a general pathological pattern and not a disease-specific mechanism. Thus, their potential suitability for clinical diagnostic purposes requires further investigation. The development of new assays for 
the detection of neurodegenerative processes is crucial to prevent misdiagnosis and to accelerate diagnosis upon onset of symptoms.

Authors contributions Conceptualization [NGdSJ, PO, MO] Literature search and data analysis: [NGdSJ]; Writing—original draft preparation: [NGdSJ]; Artwork and Illustrations [NGdSJ, FM]; Review and editing: [FM, SH, PO, PS, MO]. All authors read and approved the final manuscript.

Funding Open Access funding enabled and organized by Projekt DEAL. This project has received funding from the European Union's Horizon 2020 research and innovation programme under the Marie Skłodowska-Curie grant agreement No 860197.

\section{Declarations}

Conflict of interest The authors have no conflicts of interest to declare that are relevant to the content of this article.

Availability of data and material Not applicable.

Code availability Not applicable.

Ethics approval Not applicable.

Consent to participate Not applicable.

Consent for publication Not applicable.

Open Access This article is licensed under a Creative Commons Attribution 4.0 International License, which permits use, sharing, adaptation, distribution and reproduction in any medium or format, as long as you give appropriate credit to the original author(s) and the source, provide a link to the Creative Commons licence, and indicate if changes were made. The images or other third party material in this article are included in the article's Creative Commons licence, unless indicated otherwise in a credit line to the material. If material is not included in the article's Creative Commons licence and your intended use is not permitted by statutory regulation or exceeds the permitted use, you will need to obtain permission directly from the copyright holder. To view a copy of this licence, visit http://creativecommons.org/licenses/by/4.0/.

\section{References}

Abad MA, Enguita M, DeGregorio-Rocasolano N, Ferrer I, Trullas R (2006) Neuronal pentraxin 1 contributes to the neuronal damage evoked by amyloid-beta and is overexpressed in dystrophic neurites in Alzheimer's brain. J Neurosci 26:12735-12747. https:// doi.org/10.1523/JNEUROSCI.0575-06.2006

Al Rahim M, Hossain MA (2013) Genetic deletion of NP1 prevents hypoxic-ischemic neuronal death via reducing AMPA receptor synaptic localization in hippocampal neurons. J Am Heart Assoc 2:e006098. https://doi.org/10.1161/JAHA.112.006098

Baig S, Wilcock GK, Love S (2005) Loss of perineuronal net $N$-acetylgalactosamine in Alzheimer's disease. Acta Neuropathol 110:393-401. https://doi.org/10.1007/s00401-005-1060-2

Bang J, Spina S, Miller BL (2015) Frontotemporal dementia. Lancet 386:1672-1682. https://doi.org/10.1016/S0140-6736(15)00461-4
Barschke P, Oeckl P, Steinacker P, Al Shweiki MR, Weishaupt JH, Landwehrmeyer GB, Anderl-Straub S, Weydt P, Diehl-Schmid J, Danek A, Kornhuber J, Schroeter ML, Prudlo J, Jahn H, Fassbender K, Lauer M, van der Ende EL, van Swieten JC, Volk AE, Ludolph AC, Otto M, German FTLD consortium (2020) Different CSF protein profiles in amyotrophic lateral sclerosis and frontotemporal dementia with $\mathrm{C} 9$ orf72 hexanucleotide repeat expansion. J Neurol Neurosurg Psychiatry 91:503-511. https:// doi.org/10.1136/jnnp-2019-322476

Bartolini A, Di Paolo D, Noghero A, Murgia D, Sementa AR, Cilli M, Pasqualini R, Arap W, Bussolino F, Ponzoni M, Pastorino F, Marchiò S (2015) The neuronal pentraxin-2 pathway is an unrecognized target in human neuroblastoma, which also offers prognostic value in patients. Cancer Res 75:4265-4271. https:// doi.org/10.1158/0008-5472.CAN-15-0649

Begcevic I, Tsolaki M, Brinc D, Brown M, Martinez-Morillo E, Lazarou I, Kozori M, Tagaraki F, Nenopoulou S, Gkioka M, Lazarou E, Lim B, Batruch I, Diamandis EP (2018) Neuronal pentraxin receptor- 1 is a new cerebrospinal fluid biomarker of Alzheimer's disease progression. F1000Res 7:1012. https://doi.org/10.12688/ f1000research.15095.1

Belbin O, Xiao M-F, Xu D, Carmona-Iragui M, Pegueroles J, Benejam B, Videla L, Fernández S, Barroeta I, Nuñez-Llaves R, Montal V, Vilaplana E, Altuna M, Clarimón J, Alcolea D, Blesa R, Lleó A, Worley PF, Fortea J (2020) Cerebrospinal fluid profile of NPTX2 supports role of Alzheimer's disease-related inhibitory circuit dysfunction in adults with Down syndrome. Mol Neurodegener 15:46. https://doi.org/10.1186/s13024-020-00398-0

Belforte JE, Zsiros V, Sklar ER, Jiang Z, Yu G, Li Y, Quinlan EM, Nakazawa K (2010) Postnatal NMDA receptor ablation in corticolimbic interneurons confers schizophrenia-like phenotypes. Nat Neurosci 13:76-83. https://doi.org/10.1038/nn.2447

Bereczki E, Bogstedt A, Höglund K, Tsitsi P, Brodin L, Ballard C, Svenningsson P, Aarsland D (2017) Synaptic proteins in CSF relate to Parkinson's disease stage markers. NPJ Parkinsons Dis 3:7. https://doi.org/10.1038/s41531-017-0008-2

Berretta S, Pantazopoulos H, Markota M, Brown C, Batzianouli ET (2015) Losing the sugar coating: potential impact of perineuronal net abnormalities on interneurons in schizophrenia. Schizophr Res 167:18-27. https://doi.org/10.1016/j.schres.2014.12.040

Bjartmar L, Huberman AD, Ullian EM, Rentería RC, Liu X, Xu W, Prezioso J, Susman MW, Stellwagen D, Stokes CC, Cho R, Worley P, Malenka RC, Ball S, Peachey NS, Copenhagen D, Chapman B, Nakamoto M, Barres BA, Perin MS (2006) Neuronal pentraxins mediate synaptic refinement in the developing visual system. J Neurosci 26:6269-6281. https://doi.org/10.1523/ JNEUROSCI.4212-05.2006

Black RA (2002) Tumor necrosis factor- $\alpha$ converting enzyme. Int J Biochem Cell Biol 34:1-5. https://doi.org/10.1016/S13572725(01)00097-8

Blennow K, Zetterberg H (2018) Biomarkers for Alzheimer's disease: current status and prospects for the future. J Intern Med 284:643663. https://doi.org/10.1111/joim.12816

Blennow K, Hampel H, Weiner M, Zetterberg H (2010) Cerebrospinal fluid and plasma biomarkers in Alzheimer disease. Nat Rev Neurol 6:131-144. https://doi.org/10.1038/nrneurol.2010.4

Boiten WA, van Steenoven I, Xiao M, Worley PF, Lemstra AW, Teunissen CE (2020) Pathologically decreased CSF levels of synaptic marker NPTX2 in DLB are correlated with levels of alphasynuclein and VGF. Cells 10:38. https://doi.org/10.3390/cells 10010038

Boles NC, Hirsch SE, Le S, Corneo B, Najm F, Minotti AP, Wang Q, Lotz S, Tesar PJ, Fasano CA (2014) NPTX1 regulates neural lineage specification from human pluripotent stem cells. Cell Rep 6:724-736. https://doi.org/10.1016/j.celrep.2014.01.026 
Bonansco C, Fuenzalida M (2016) Plasticity of hippocampal excitatory-inhibitory balance: missing the synaptic control in the epileptic brain. Neural Plast 2016:8607038. https://doi.org/10. $1155 / 2016 / 8607038$

Bottazzi B, Doni A, Garlanda C, Mantovani A (2010) An integrated view of humoral innate immunity: pentraxins as a paradigm. Annu Rev Immunol 28:157-183. https://doi.org/10.1146/annur ev-immunol-030409-101305

Bozzi Y, Provenzano G, Casarosa S (2018) Neurobiological bases of autism-epilepsy comorbidity: a focus on excitation/inhibition imbalance. Eur J Neurosci 47:534-548. https://doi.org/10.1111/ ejn. 13595

Brady DR, Mufson EJ (1997) Parvalbumin-immunoreactive neurons in the hippocampal formation of Alzheimer's diseased brain. Neuroscience 80:1113-1125. https://doi.org/10.1016/s0306-4522(97) 00068-7

Brett M, Anton J-L, Valabregue R, Poline J-B (2002) Region of interest analysis using the MarsBar toolbox for SPM 99. Neuroimage 16:497

Breviario F, d'Aniello EM, Golay J, Peri G, Bottazzi B, Bairoch A, Saccone S, Marzella R, Predazzi V, Rocchi M (1992) Interleukin1 -inducible genes in endothelial cells. Cloning of a new gene related to C-reactive protein and serum amyloid $\mathrm{P}$ component. J Biol Chem 267:22190-22197

Bright F, Werry EL, Dobson-Stone C, Piguet O, Ittner LM, Halliday GM, Hodges JR, Kiernan MC, Loy CT, Kassiou M, Kril JJ (2019) Neuroinflammation in frontotemporal dementia. Nat Rev Neurol 15:540-555. https://doi.org/10.1038/s41582-019-0231-z

Brinkmalm G, Sjödin S, Simonsen AH, Hasselbalch SG, Zetterberg H, Brinkmalm A, Blennow K (2018) A parallel reaction monitoring mass spectrometric method for analysis of potential CSF biomarkers for Alzheimer's disease. Proteomics Clin Appl. https:// doi.org/10.1002/prca.201700131

Camporesi E, Nilsson J, Brinkmalm A, Becker B, Ashton NJ, Blennow K, Zetterberg H (2020) Fluid biomarkers for synaptic dysfunction and loss. Biomarker Insights 15:1177271920950319. https://doi. org/10.1177/1177271920950319

Caputi A, Fuchs EC, Allen K, Le Magueresse C, Monyer H (2012) Selective reduction of AMPA currents onto hippocampal interneurons impairs network oscillatory activity. PLoS ONE 7:e37318. https://doi.org/10.1371/journal.pone.0037318

Carceller H, Guirado R, Ripolles-Campos E, Teruel-Marti V, Nacher J (2020) Perineuronal nets regulate the inhibitory perisomatic input onto parvalbumin interneurons and $\gamma$ activity in the prefrontal cortex. J Neurosci 40:5008-5018. https://doi.org/10.1523/ JNEUROSCI.0291-20.2020

Cardin JA, Carlén M, Meletis K, Knoblich U, Zhang F, Deisseroth K, Tsai L-H, Moore CI (2009) Driving fast-spiking cells induces gamma rhythm and controls sensory responses. Nature 459:663667. https://doi.org/10.1038/nature08002

Chang MC, Park JM, Pelkey KA, Grabenstatter HL, Xu D, Linden DJ, Sutula TP, McBain CJ, Worley PF (2010) Narp regulates homeostatic scaling of excitatory synapses on parvalbumin-expressing interneurons. Nat Neurosci 13:1090-1097. https://doi.org/10. $1038 / \mathrm{nn} .2621$

Charbonnier-Beaupel F, Malerbi M, Alcacer C, Tahiri K, Carpentier W, Wang C, During M, Xu D, Worley PF, Girault J-A, Hervé D, Corvol J-C (2015) Gene expression analyses identify narp contribution in the development of 1-DOPA-induced dyskinesia. J Neurosci 35:96-111. https://doi.org/10.1523/JNEUROSCI. 5231-13.2015

Chen B, Bixby JL (2005) Neuronal pentraxin with chromo domain (NPCD) is a novel class of protein expressed in multiple neuronal domains. J Comp Neurol 481:391-402. https://doi.org/10.1002/ cne. 20391
Cho RW, Park JM, Wolff SBE, Xu D, Hopf C, Kim J-A, Reddy RC, Petralia RS, Perin MS, Linden DJ, Worley PF (2008) mGluR1/5dependent long-term depression requires the regulated ectodomain cleavage of neuronal pentraxin NPR by TACE. Neuron 57:858-871. https://doi.org/10.1016/j.neuron.2008.01.010

Clayton KB, Podlesniy P, Figueiro-Silva J, López-Doménech G, Benitez L, Enguita M, Abad MA, Soriano E, Trullas R (2012) NP1 regulates neuronal activity-dependent accumulation of BAX in mitochondria and mitochondrial dynamics. J Neurosci 32:14531466. https://doi.org/10.1523/JNEUROSCI.4604-11.2012

Crocker A, España RA, Papadopoulou M, Saper CB, Faraco J, Sakurai T, Honda M, Mignot E, Scammell TE (2005) Concomitant loss of dynorphin, NARP, and orexin in narcolepsy. Neurology 65:1184-1188. https://doi.org/10.1212/01.wnl.0000168173. 71940.ab

Cummings DM, Benway TA, Ho H, Tedoldi A, Fernandes Freitas MM, Shahab L, Murray CE, Richard-Loendt A, Brandner S, Lashley T, Salih DA, Edwards FA (2017) Neuronal and peripheral pentraxins modify glutamate release and may interact in blood-brain barrier failure. Cereb Cortex 27:3437-3448. https://doi.org/10.1093/cercor/bhx046

Davies CA, Mann DM, Sumpter PQ, Yates PO (1987) A quantitative morphometric analysis of the neuronal and synaptic content of the frontal and temporal cortex in patients with Alzheimer's disease. J Neurol Sci 78:151-164. https://doi.org/10.1016/ 0022-510x(87)90057-8

DeGregorio-Rocasolano N, Gasull T, Trullas R (2001) Overexpression of neuronal pentraxin 1 is involved in neuronal death evoked by low $\mathrm{K}(+)$ in cerebellar granule cells. J Biol Chem 276:796-803. https://doi.org/10.1074/jbc.M007967200

DeKosky ST, Scheff SW (1990) Synapse loss in frontal cortex biopsies in Alzheimer's disease: correlation with cognitive severity. Ann Neurol 27:457-464. https://doi.org/10.1002/ana.41027 0502

Dickerson BC, Salat DH, Greve DN, Chua EF, Rand-Giovannetti E, Rentz DM, Bertram L, Mullin K, Tanzi RE, Blacker D, Albert MS, Sperling RA (2005) Increased hippocampal activation in mild cognitive impairment compared to normal aging and $\mathrm{AD}$. Neurology 65:404-411. https://doi.org/10.1212/01.wnl.00001 71450.97464 .49

Dodds DC, Omeis IA, Cushman SJ, Helms JA, Perin MS (1997) Neuronal pentraxin receptor, a novel putative integral membrane pentraxin that interacts with neuronal pentraxin 1 and 2 and taipoxin-associated calcium-binding protein 49. J Biol Chem 272:21488-21494. https://doi.org/10.1074/jbc.272.34.21488

Dong X, Wang Y, Qin Z (2009) Molecular mechanisms of excitotoxicity and their relevance to pathogenesis of neurodegenerative diseases. Acta Pharmacol Sin 30:379-387. https://doi.org/10. 1038/aps.2009.24

Dorsey DA, Mascó DH, Dikranian K, Hyrc K, Masciotra L, Faddis B, Soriano M, Gru AA, Goldberg MP, de Erausquin GA (2006) Ultrastructural characterization of alpha-amino-3-hydroxy-5-methyl-4-isoxazolepropionic acid-induced cell death in embryonic dopaminergic neurons. Apoptosis 11:535-544. https://doi.org/ 10.1007/s10495-006-5268-y

Dowton SB, McGrew SD (1990) Rat serum amyloid P component. Analysis of cDNA sequence and gene expression. Biochemical Journal 270:553-556. https://doi.org/10.1042/bj2700553

Driscoll I, Troncoso J (2011) Asymptomatic Alzheimer's disease: a prodrome or a state of resilience? Curr Alzheimer Res 8:330 335. https://doi.org/10.2174/156720511795745348

Duits FH, Brinkmalm G, Teunissen CE, Brinkmalm A, Scheltens P, Van der Flier WM, Zetterberg H, Blennow K (2018) Synaptic proteins in CSF as potential novel biomarkers for prognosis in prodromal Alzheimer's disease. Alzheimers Res Ther 10:5. https://doi.org/10.1186/s13195-017-0335-x 
Eastwood SL, Harrison PJ (2010) Markers of glutamate synaptic transmission and plasticity are increased in the anterior cingulate cortex in bipolar disorder. Biol Psychiatry 67:1010-1016. https:// doi.org/10.1016/j.biopsych.2009.12.004

Emsley J, White HE, O’Hara BP, Oliva G, Srinivasan N, Tickle IJ, Blundell TL, Pepys MB, Wood SP (1994) Structure of pentameric human serum amyloid P component. Nature 367:338-345. https://doi.org/10.1038/367338a0

Farhy-Tselnicker I, van Casteren ACM, Lee A, Chang VT, Aricescu AR, Allen NJ (2017) Astrocyte-secreted glypican 4 regulates release of neuronal pentraxin 1 from axons to induce functional synapse formation. Neuron 96:428-445.e13. https://doi.org/10. 1016/j.neuron.2017.09.053

Ferguson BR, Gao W-J (2018) PV interneurons: critical regulators of $\mathrm{E} / \mathrm{I}$ balance for prefrontal cortex-dependent behavior and psychiatric disorders. Front Neural Circuits 12:37. https://doi.org/10. 3389/fncir.2018.00037

Figueiro-Silva J, Gruart A, Clayton KB, Podlesniy P, Abad MA, Gasull X, Delgado-García JM, Trullas R (2015) Neuronal pentraxin 1 negatively regulates excitatory synapse density and synaptic plasticity. J Neurosci 35:5504-5521. https://doi.org/10.1523/JNEUR OSCI.2548-14.2015

Findley CA, Bartke A, Hascup KN, Hascup ER (2019) Amyloid beta-related alterations to glutamate signaling dynamics during Alzheimer's disease progression. ASN Neuro 11:1759091419855541. https://doi.org/10.1177/1759091419 855541

Foss-Feig JH, Adkinson BD, Ji JL, Yang G, Srihari VH, McPartland JC, Krystal JH, Murray JD, Anticevic A (2017) Searching for cross-diagnostic convergence: neural mechanisms governing excitation and inhibition balance in schizophrenia and autism spectrum disorders. Biol Psychiat 81:848-861. https://doi.org/ 10.1016/j.biopsych.2017.03.005

Fuchs EC, Zivkovic AR, Cunningham MO, Middleton S, Lebeau FEN, Bannerman DM, Rozov A, Whittington MA, Traub RD, Rawlins JNP, Monyer H (2007) Recruitment of parvalbumin-positive interneurons determines hippocampal function and associated behavior. Neuron 53:591-604. https://doi.org/10.1016/j.neuron. 2007.01.031

Galasko D, Xiao M, Xu D, Smirnov D, Salmon DP, Dewit N, Vanbrabant J, Jacobs D, Vanderstichele H, Vanmechelen E, Worley P (2019) Synaptic biomarkers in CSF aid in diagnosis, correlate with cognition and predict progression in MCI and Alzheimer's disease. Alzheimers Dement (n y) 5:871-882. https://doi.org/10. 1016/j.trci.2019.11.002

Gallo FT, Katche C, Morici JF, Medina JH, Weisstaub NV (2018) Immediate early genes, memory and psychiatric disorders: focus on c-Fos, Egr1 and Arc. Front Behav Neurosci 12:79. https://doi. org/10.3389/fnbeh.2018.00079

Gao R, Penzes P (2015) Common mechanisms of excitatory and inhibitory imbalance in schizophrenia and autism spectrum disorders. Curr Mol Med 15:146-167. https://doi.org/10.2174/1566524015 666150303003028

Garlanda C, Bottazzi B, Bastone A, Mantovani A (2005) Pentraxins at the crossroads between innate immunity, inflammation, matrix deposition, and female fertility. Annu Rev Immunol 23:337-366. https://doi.org/10.1146/annurev.immunol.23.021704.115756

Gascon E, Lynch K, Ruan H, Almeida S, Verheyden JM, Seeley WW, Dickson DW, Petrucelli L, Sun D, Jiao J, Zhou H, Jakovcevski M, Akbarian S, Yao W-D, Gao F-B (2014) Alterations in microRNA-124 and AMPA receptors contribute to social behavioral deficits in frontotemporal dementia. Nat Med 20:1444-1451. https://doi.org/10.1038/nm.3717

Gilbert J, Man H-Y (2017) Fundamental elements in autism: from neurogenesis and neurite growth to synaptic plasticity. Front Cell Neurosci 11:359. https://doi.org/10.3389/fncel.2017.00359
Goetzl EJ, Abner EL, Jicha GA, Kapogiannis D, Schwartz JB (2018) Declining levels of functionally specialized synaptic proteins in plasma neuronal exosomes with progression of Alzheimer's disease. FASEB J 32:888-893. https://doi.org/10.1096/fj.20170 0731R

Gong Y, Lippa CF (2010) Review: disruption of the postsynaptic density in Alzheimer's disease and other neurodegenerative dementias. Am J Alzheimers Dis Other Demen 25:547-555. https://doi. org/10.1177/1533317510382893

Gu Y, Huang S, Chang MC, Worley P, Kirkwood A, Quinlan EM (2013) Obligatory role for the immediate early gene NARP in critical period plasticity. Neuron 79:335-346. https://doi.org/10. 1016/j.neuron.2013.05.016

Halbgebauer S, Oeckl P, Steinacker P, Yilmazer-Hanke D, AnderlStraub S, von Arnim C, Froelich L, Gomes LA, Hausner L, Huss A, Jahn H, Weishaupt J, Ludolph AC, Thal DR, Otto M (2020) Beta-synuclein in cerebrospinal fluid as an early diagnostic marker of Alzheimer's disease. J Neurol Neurosurg Psychiatry. https://doi.org/10.1136/jnnp-2020-324306

Härtig W, Derouiche A, Welt K, Brauer K, Grosche J, Mäder M, Reichenbach A, Brückner G (1999) Cortical neurons immunoreactive for the potassium channel Kv3.1b subunit are predominantly surrounded by perineuronal nets presumed as a buffering system for cations. Brain Res 842:15-29. https://doi. org/10.1016/s0006-8993(99)01784-9

Hawrylycz MJ, Lein ES, Guillozet-Bongaarts AL, Shen EH, Ng L, Miller JA, van de Lagemaat LN, Smith KA, Ebbert A, Riley ZL, Abajian C, Beckmann CF, Bernard A, Bertagnolli D, Boe AF, Cartagena PM, Chakravarty MM, Chapin M, Chong J, Dalley RA, David Daly B, Dang C, Datta S, Dee N, Dolbeare TA, Faber V, Feng D, Fowler DR, Goldy J, Gregor BW, Haradon Z, Haynor DR, Hohmann JG, Horvath S, Howard RE, Jeromin A, Jochim JM, Kinnunen M, Lau C, Lazarz ET, Lee C, Lemon TA, Li L, Li Y, Morris JA, Overly CC, Parker PD, Parry SE, Reding M, Royall JJ, Schulkin J, Sequeira PA, Slaughterbeck CR, Smith SC, Sodt AJ, Sunkin SM, Swanson BE, Vawter MP, Williams D, Wohnoutka P, Zielke HR, Geschwind DH, Hof PR, Smith SM, Koch C, Grant SGN, Jones AR (2012) An anatomically comprehensive atlas of the adult human brain transcriptome. Nature 489, 391-399. Doi: https://doi.org/10. 1038/nature11405. (C) 2010 Allen Institute for Brain Science. Allen Human Brain Atlas. Available from: human.brain-map. org. NPTX1 - http://human.brain-map.org/microarray/search/ show? exact_match $=$ true $\&$ search_term $=$ NPTX $1 \&$ search type=gene. NPTX2-http://human.brain-map.org/microarray/ search/show? exact_match $=$ true\&search_term $=$ NPTX2 \& search_type $=$ gene $\&$ page_num $=0$. NPTXR-http://human. brain-map.org/microarray/search/show? exact_match $=$ true $\&$ search_term $=$ NPTXR $\&$ search_type $=$ gene $\&$ page_num $=0$. Accessed 13 May 2021

Hendrickson RC, Lee AYH, Song Q, Liaw A, Wiener M, Paweletz CP, Seeburger JL, Li J, Meng F, Deyanova EG, Mazur MT, Settlage RE, Zhao X, Southwick K, Du Y, Holder D, Sachs JR, Laterza OF, Dallob A, Chappell DL, Snyder K, Modur V, King E, Joachim C, Bondarenko AY, Shearman M, Soper KA, Smith AD, Potter WZ, Koblan KS, Sachs AB, Yates NA (2015) High resolution discovery proteomics reveals candidate disease progression markers of Alzheimer's disease in human cerebrospinal fluid. PLoS ONE 10:e0135365. https://doi.org/10.1371/journal. pone. 0135365

Henstridge CM, Hyman BT, Spires-Jones TL (2019) Beyond the neuron-cellular interactions early in Alzheimer disease pathogenesis. Nat Rev Neurosci 20:94-108. https://doi.org/10.1038/ s41583-018-0113-1

Howard MW, Rizzuto DS, Caplan JB, Madsen JR, Lisman J, Aschenbrenner-Scheibe R, Schulze-Bonhage A, Kahana MJ (2003) 
Gamma oscillations correlate with working memory load in humans. Cereb Cortex 13:1369-1374. https://doi.org/10.1093/ cercor/bhg084

Hsu YC, Perin MS (1995) Human neuronal pentraxin II (NPTX2): conservation, genomic structure, and chromosomal localization. Genomics 28:220-227. https://doi.org/10.1006/geno.1995.1134

Hu J-H, Park JM, Park S, Xiao B, Dehoff MH, Kim S, Hayashi T, Schwarz MK, Huganir RL, Seeburg PH, Linden DJ, Worley PF (2010) Homeostatic scaling requires group I mGluR activation mediated by Homer1a. Neuron 68:1128-1142. https://doi.org/ 10.1016/j.neuron.2010.11.008

Hu H, Gan J, Jonas P (2014) Fast-spiking, parvalbumin+ GABAergic interneurons: from cellular design to microcircuit function. Science 345:1255263. https://doi.org/10.1126/science.1255263

Huo L, Wang B, Zheng M, Zhang Y, Xu J, Yang G, Guan Q (2019) miR-128-3p inhibits glioma cell proliferation and differentiation by targeting NPTX1 through IRS-1/PI3K/AKT signaling pathway. Exp Ther Med 17:2921-2930. https://doi.org/10.3892/ etm.2019.7284

Iaccarino HF, Singer AC, Martorell AJ, Rudenko A, Gao F, Gillingham TZ, Mathys H, Seo J, Kritskiy O, Abdurrob F, Adaikkan C, Canter RG, Rueda R, Brown EN, Boyden ES, Tsai L-H (2016) Gamma frequency entrainment attenuates amyloid load and modifies microglia. Nature 540:230-235. https://doi.org/10. 1038/nature20587

Jack CR, Holtzman DM (2013) Biomarker modeling of Alzheimer's disease. Neuron 80:1347-1358. https://doi.org/10.1016/j.neuron. 2013.12.003

Janezic S, Threlfell S, Dodson PD, Dowie MJ, Taylor TN, Potgieter D, Parkkinen L, Senior SL, Anwar S, Ryan B, Deltheil T, Kosillo P, Cioroch M, Wagner K, Ansorge O, Bannerman DM, Bolam JP, Magill PJ, Cragg SJ, Wade-Martins R (2013) Deficits in dopaminergic transmission precede neuron loss and dysfunction in a new Parkinson model. Proc Natl Acad Sci USA 110:E4016-4025. https://doi.org/10.1073/pnas.1309143110

Jumper J, Evans R, Pritzel A, Green T, Figurnov M, Ronneberger O, Tunyasuvunakool K, Bates R, Žídek A, Potapenko A, Bridgland A, Meyer C, Kohl SAA, Ballard AJ, Cowie A, Romera-Paredes B, Nikolov S, Jain R, Adler J, Back T, Petersen S, Reiman D, Clancy E, Zielinski M, Steinegger M, Pacholska M, Berghammer T, Bodenstein S, Silver D, Vinyals O, Senior AW, Kavukcuoglu K, Kohli P, Hassabis D (2021) Highly accurate protein structure prediction with AlphaFold. Nature. https://doi.org/10.1038/ s41586-021-03819-2

Kamenetz F, Tomita T, Hsieh H, Seabrook G, Borchelt D, Iwatsubo T, Sisodia S, Malinow R (2003) APP processing and synaptic function. Neuron 37:925-937. https://doi.org/10.1016/s08966273(03)00124-7

Khundakar AA, Hanson PS, Erskine D, Lax NZ, Roscamp J, Karyka E, Tsefou E, Singh P, Cockell SJ, Gribben A, Ramsay L, Blain PG, Mosimann UP, Lett DJ, Elstner M, Turnbull DM, Xiang CC, Brownstein MJ, O'Brien JT, Taylor J-P, Attems J, Thomas AJ, McKeith IG, Morris CM (2016) Analysis of primary visual cortex in dementia with Lewy bodies indicates GABAergic involvement associated with recurrent complex visual hallucinations. Acta Neuropathol Commun 4:66. https://doi.org/10.1186/ s40478-016-0334-3

Kirkpatrick LL, Matzuk MM, Dodds DC, Perin MS (2000) Biochemical interactions of the neuronal pentraxins. Neuronal pentraxin (NP) receptor binds to taipoxin and taipoxin-associated calciumbinding protein 49 via NP1 and NP2. J Biol Chem 275:1778617792. https://doi.org/10.1074/jbc.M002254200

Korotkova T, Fuchs EC, Ponomarenko A, von Engelhardt J, Monyer H (2010) NMDA receptor ablation on parvalbumin-positive interneurons impairs hippocampal synchrony, spatial representations, and working memory. Neuron 68:557-569. https://doi.org/10.1016/j.neuron.2010.09.017

Kovács RÁ, Vadászi H, Bulyáki É, Török G, Tóth V, Mátyás D, Kun J, Hunyadi-Gulyás É, Fedor FZ, Csincsi Á, Medzihradszky K, Homolya L, Juhász G, Kékesi KA, Józsi M, Györffy BA, Kardos $\mathbf{J}$ (2020) Identification of neuronal pentraxins as synaptic binding partners of C1q and the involvement of NP1 in synaptic pruning in adult mice. Front Immunol 11:599771. https://doi.org/10. 3389/fimmu.2020.599771

Kroksveen AC, Guldbrandsen A, Vedeler C, Myhr KM, Opsahl JA, Berven FS (2012) Cerebrospinal fluid proteome comparison between multiple sclerosis patients and controls. Acta Neurol Scand 126:90-96. https://doi.org/10.1111/ane.12029

Kvartsberg H, Portelius E, Andreasson U, Brinkmalm G, Hellwig K, Lelental N, Kornhuber J, Hansson O, Minthon L, Spitzer P, Maler JM, Zetterberg H, Blennow K, Lewczuk P (2015) Characterization of the postsynaptic protein neurogranin in paired cerebrospinal fluid and plasma samples from Alzheimer's disease patients and healthy controls. Alzheimers Res Ther 7:40. https:// doi.org/10.1186/s13195-015-0124-3

Lang Y, Li Y, Yu H, Lin L, Chen X, Wang S, Zhang H (2020) HOTAIR drives autophagy in midbrain dopaminergic neurons in the substantia nigra compacta in a mouse model of Parkinson's disease by elevating NPTX2 via miR-221-3p binding. Aging (albany NY) 12:7660-7678. https://doi.org/10.18632/aging.103028

Lee GW, Lee TH, Vilcek J (1993) TSG-14, a tumor necrosis factor- and IL-1-inducible protein, is a novel member of the pentraxin family of acute phase proteins. J Immunol 150:1804-1812

Lee S-J, Wei M, Zhang C, Maxeiner S, Pak C, Calado Botelho S, Trotter J, Sterky FH, Südhof TC (2017) Presynaptic neuronal pentraxin receptor organizes excitatory and inhibitory synapses. J Neurosci 37:1062-1080. https://doi.org/10.1523/JNEUROSCI. 2768-16.2016

Lepeta K, Lourenco MV, Schweitzer BC, Martino Adami PV, Banerjee P, Catuara-Solarz S, de La Fuente Revenga M, Guillem AM, Haidar M, Ijomone OM, Nadorp B, Qi L, Perera ND, Refsgaard LK, Reid KM, Sabbar M, Sahoo A, Schaefer N, Sheean RK, Suska A, Verma R, Vicidomini C, Wright D, Zhang X-D, Seidenbecher C (2016) Synaptopathies: synaptic dysfunction in neurological disorders-a review from students to students. J Neurochem 138:785-805. https://doi.org/10.1111/jnc.13713

Levenga J, Krishnamurthy P, Rajamohamedsait H, Wong H, Franke TF, Cain P, Sigurdsson EM, Hoeffer CA (2013) Tau pathology induces loss of GABAergic interneurons leading to altered synaptic plasticity and behavioral impairments. Acta Neuropathol Commun 1:34. https://doi.org/10.1186/2051-5960-1-34

Lewis DA, Hashimoto T, Volk DW (2005) Cortical inhibitory neurons and schizophrenia. Nat Rev Neurosci 6:312-324. https://doi.org/ $10.1038 /$ nrn 1648

Libiger O, Shaw LM, Watson MH, Nairn AC, Umaña KL, Biarnes MC, Canet-Avilés RM, Jack CR, Breton Y-A, Cortes L, Chelsky D, Spellman DS, Baker SA, Raghavan N, Potter WZ (2021) Longitudinal CSF proteomics identifies NPTX2 as a prognostic biomarker of Alzheimer's disease. Alzheimers Dement. https:// doi.org/10.1002/alz.12353

Lim B, Tsolaki M, Soosaipillai A, Brown M, Zilakaki M, Tagaraki F, Fotiou D, Koutsouraki E, Grosi E, Prassas I, Diamandis EP (2019) Liquid biopsy of cerebrospinal fluid identifies neuronal pentraxin receptor (NPTXR) as a biomarker of progression of Alzheimer's disease. Clin Chem Lab Med 57:1875-1881. https:// doi.org/10.1515/cclm-2019-0428

Lim B, Sando SB, Grøntvedt GR, Bråthen G, Diamandis EP (2020) Cerebrospinal fluid neuronal pentraxin receptor as a biomarker of long-term progression of Alzheimer's disease: a 24-month follow-up study. Neurobiol Aging 93:97.e1-97.e7. https://doi.org/ 10.1016/j.neurobiolaging.2020.03.013 
Lima Giacobbo B, Doorduin J, Klein HC, Dierckx RAJO, Bromberg E, de Vries EFJ (2019) Brain-derived neurotrophic factor in brain disorders: focus on neuroinflammation. Mol Neurobiol 56:32953312. https://doi.org/10.1007/s12035-018-1283-6

Ling S-C (2018) Synaptic paths to neurodegeneration: the emerging role of TDP-43 and FUS in synaptic functions. Neural Plast 2018:e8413496. https://doi.org/10.1155/2018/8413496

Llano DA, Bundela S, Mudar RA, Devanarayan V, Alzheimer's Disease Neuroimaging Initiative (ADNI) (2017) A multivariate predictive modeling approach reveals a novel CSF peptide signature for both Alzheimer's Disease state classification and for predicting future disease progression. PLoS ONE 12:e0182098. https://doi. org/10.1371/journal.pone.0182098

Lleó A, Núñez-Llaves R, Alcolea D, Chiva C, Balateu-Paños D, Colom-Cadena M, Gomez-Giro G, Muñoz L, Querol-Vilaseca M, Pegueroles J, Rami L, Lladó A, Molinuevo JL, Tainta M, Clarimón J, Spires-Jones T, Blesa R, Fortea J, Martínez-Lage P, Sánchez-Valle R, Sabidó E, Bayés À, Belbin O (2019) Changes in synaptic proteins precede neurodegeneration markers in preclinical Alzheimer's disease cerebrospinal fluid. Mol Cell Proteomics 18:546-560. https://doi.org/10.1074/mcp.RA118.001290

Lopes MW, Soares FMS, de Mello N, Nunes JC, Cajado AG, de Brito D, de Cordova FM, da Cunha RMS, Walz R, Leal RB (2013) Time-dependent modulation of AMPA receptor phosphorylation and mRNA expression of NMDA receptors and glial glutamate transporters in the rat hippocampus and cerebral cortex in a pilocarpine model of epilepsy. Exp Brain Res 226:153-163. https:// doi.org/10.1007/s00221-013-3421-8

Lui H, Zhang J, Makinson SR, Cahill MK, Kelley KW, Huang H-Y, Shang Y, Oldham MC, Martens LH, Gao F, Coppola G, Sloan SA, Hsieh CL, Kim CC, Bigio EH, Weintraub S, Mesulam M-M, Rademakers R, Mackenzie IR, Seeley WW, Karydas A, Miller BL, Borroni B, Ghidoni R, Farese RV, Paz JT, Barres BA, Huang EJ (2016) Progranulin deficiency promotes circuit-specific synaptic pruning by microglia via complement activation. Cell 165:921-935. https://doi.org/10.1016/j.cell.2016.04.001

Ma Q-L, Teng E, Zuo X, Jones M, Teter B, Zhao EY, Zhu C, Bilousova T, Gylys KH, Apostolova LG, LaDu MJ, Hossain MA, Frautschy SA, Cole GM (2018) Neuronal pentraxin 1: A synapticderived plasma biomarker in Alzheimer's disease. Neurobiol Dis 114:120-128. https://doi.org/10.1016/j.nbd.2018.02.014

Magdalinou NK, Noyce AJ, Pinto R, Lindstrom E, Holmén-Larsson J, Holtta M, Blennow K, Morris HR, Skillbäck T, Warner TT, Lees AJ, Pike I, Ward M, Zetterberg H, Gobom J (2017) Identification of candidate cerebrospinal fluid biomarkers in parkinsonism using quantitative proteomics. Parkinsonism Relat Disord 37:65-71. https://doi.org/10.1016/j.parkreldis.2017.01.016

Maheshwari A, Nahm WK, Noebels JL (2013) Paradoxical proepileptic response to NMDA receptor blockade linked to cortical interneuron defect in stargazer mice. Front Cell Neurosci 7:156. https:// doi.org/10.3389/fncel.2013.00156

Mariga A, Glaser J, Mathias L, Xu D, Xiao M, Worley P, Ninan I, Chao MV (2015) Definition of a bidirectional activity-dependent pathway involving BDNF and Narp. Cell Rep 13:1747-1756. https:// doi.org/10.1016/j.celrep.2015.10.064

Martinez de la Torre Y, Fabbri M, Jaillon S, Bastone A, Nebuloni M, Vecchi A, Mantovani A, Garlanda C (2010) Evolution of the pentraxin family: the new entry PTX4. J Immunol 184:5055-5064. https://doi.org/10.4049/jimmunol.0901672

Marttinen M, Kurkinen KM, Soininen H, Haapasalo A, Hiltunen M (2015) Synaptic dysfunction and septin protein family members in neurodegenerative diseases. Mol Neurodegener 10:16. https:// doi.org/10.1186/s13024-015-0013-z

Masliah E, Mallory M, Alford M, DeTeresa R, Hansen LA, McKeel DW, Morris JC (2001) Altered expression of synaptic proteins occurs early during progression of Alzheimer's disease. Neurology 56:127-129. https://doi.org/10.1212/wnl.56.1.127

McDade E, Wang G, Gordon BA, Hassenstab J, Benzinger TLS, Buckles V, Fagan AM, Holtzman DM, Cairns NJ, Goate AM, Marcus DS, Morris JC, Paumier K, Xiong C, Allegri R, Berman SB, Klunk W, Noble J, Ringman J, Ghetti B, Farlow M, Sperling RA, Chhatwal J, Salloway S, Graff-Radford NR, Schofield PR, Masters C, Rossor MN, Fox NC, Levin J, Jucker M, Bateman RJ (2018) Longitudinal cognitive and biomarker changes in dominantly inherited Alzheimer disease. Neurology 91:e1295-e1306. https://doi.org/10.1212/WNL.0000000000006277

McGlashan TH, Hoffman RE (2000) Schizophrenia as a disorder of developmentally reduced synaptic connectivity. Arch Gen Psychiatry 57:637-648. https://doi.org/10.1001/archpsyc.57.7.637

Moran LB, Hickey L, Michael GJ, Derkacs M, Christian LM, Kalaitzakis ME, Pearce RKB, Graeber MB (2008) Neuronal pentraxin II is highly upregulated in Parkinson's disease and a novel component of Lewy bodies. Acta Neuropathol 115:471-478. https:// doi.org/10.1007/s00401-007-0309-3

Mukaetova-Ladinska EB, Andras A, Milne J, Abdel-All Z, Borr I, Jaros E, Perry RH, Honer WG, Cleghorn A, Doherty J, McIntosh G, Perry EK, Kalaria RN, McKeith IG (2013) Synaptic proteins and choline acetyltransferase loss in visual cortex in dementia with Lewy bodies. J Neuropathol Exp Neurol 72:53-60. https://doi. org/10.1097/NEN.0b013e31827c5710

Murley AG, Rouse MA, Jones PS, Ye R, Hezemans FH, O'Callaghan C, Frangou P, Kourtzi Z, Rua C, Carpenter TA, Rodgers CT, Rowe JB (2020) GABA and glutamate deficits from frontotemporal lobar degeneration are associated with disinhibition. Brain 143:3449-3462. https://doi.org/10.1093/brain/awaa305

Nelson SB, Valakh V (2015) Excitatory/inhibitory balance and circuit homeostasis in autism spectrum disorders. Neuron 87:684-698. https://doi.org/10.1016/j.neuron.2015.07.033

Nguyen M, Wong YC, Ysselstein D, Severino A, Krainc D (2019) Synaptic, mitochondrial, and lysosomal dysfunction in Parkinson's disease. Trends Neurosci 42:140-149. https://doi.org/10.1016/j. tins.2018.11.001

Nilsson J, Gobom J, Sjödin S, Brinkmalm G, Ashton NJ, Svensson J, Johansson P, Portelius E, Zetterberg H, Blennow K, Brinkmalm A (2021) Cerebrospinal fluid biomarker panel for synaptic dysfunction in Alzheimer's disease. Alzheimer's Dementia Diagn Assess Dis Monit 13:e12179. https://doi.org/10.1002/dad2.12179

Norman M, Ter-Ovanesyan D, Trieu W, Lazarovits R, Kowal EJK, Lee JH, Chen-Plotkin AS, Regev A, Church GM, Walt DR (2021) L1CAM is not associated with extracellular vesicles in human cerebrospinal fluid or plasma. Nat Methods 18:631-634. https:// doi.org/10.1038/s41592-021-01174-8

O'Brien RJ, Xu D, Petralia RS, Steward O, Huganir RL, Worley P (1999) Synaptic clustering of AMPA receptors by the extracellular immediate-early gene product Narp. Neuron 23:309-323. https://doi.org/10.1016/s0896-6273(00)80782-5

O’Brien R, Xu D, Mi R, Tang X, Hopf C, Worley P (2002) Synaptically targeted Narp plays an essential role in the aggregation of AMPA receptors at excitatory synapses in cultured spinal neurons. J Neurosci 22:4487-4498. https://doi.org/10.1523/JNEUR OSCI.22-11-04487.2002

Oeckl P, Halbgebauer S, Anderl-Straub S, von Arnim CAF, DiehlSchmid J, Froelich L, Grimmer T, Hausner L, Denk J, Jahn H, Steinacker P, Weishaupt JH, Ludolph AC, Otto M (2020) Targeted mass spectrometry suggests beta-synuclein as synaptic blood marker in Alzheimer's disease. J Proteome Res 19:1310 1318. https://doi.org/10.1021/acs.jproteome.9b00824

Omeis IA, Hsu Y-C, Perin MS (1996) Mouse and human neuronal pentraxin 1 (NPTX1): conservation, genomic structure, and chromosomal localization. Genomics 36:543-545. https://doi.org/10. 1006/geno.1996.0503 
Outeiro TF, Koss DJ, Erskine D, Walker L, Kurzawa-Akanbi M, Burn D, Donaghy P, Morris C, Taylor J-P, Thomas A, Attems J, McKeith I (2019) Dementia with Lewy bodies: an update and outlook. Mol Neurodegener 14:5. https://doi.org/10.1186/ s13024-019-0306-8

Palop JJ, Mucke L (2016) Network abnormalities and interneuron dysfunction in Alzheimer disease. Nat Rev Neurosci 17:777-792. https://doi.org/10.1038/nrn.2016.141

Pelkey KA, Barksdale E, Craig MT, Yuan X, Sukumaran M, Vargish GA, Mitchell RM, Wyeth MS, Petralia RS, Chittajallu R, Karlsson R-M, Cameron HA, Murata Y, Colonnese MT, Worley PF, McBain CJ (2015) Pentraxins coordinate excitatory synapse maturation and circuit integration of parvalbumin interneurons. Neuron 85:1257-1272. https://doi.org/10.1016/j.neuron.2015. 02.020

Pelkey KA, Chittajallu R, Craig MT, Tricoire L, Wester JC, McBain CJ (2017) Hippocampal GABAergic inhibitory interneurons. Physiol Rev 97:1619-1747. https://doi.org/10.1152/physrev. 00007.2017

Phatnani H, Maniatis T (2015) Astrocytes in neurodegenerative disease. Cold Spring Harb Perspect Biol 7:a020628. https://doi. org/10.1101/cshperspect.a020628

Pribiag H, Stellwagen D (2014) Neuroimmune regulation of homeostatic synaptic plasticity. Neuropharmacology 78:13-22. https://doi.org/10.1016/j.neuropharm.2013.06.008

Procter AW, Qurne M, Francis PT (1999) Neurochemical features of frontotemporal dementia. Dement Geriatr Cogn Disord 10(Suppl 1):80-84. https://doi.org/10.1159/000051219

Radin DP, Patel P (2017) A current perspective on the oncopreventive and oncolytic properties of selective serotonin reuptake inhibitors. Biomed Pharmacother 87:636-639. https://doi.org/ 10.1016/j.biopha.2017.01.024

Rahim MA, Thatipamula S, Hossain MA (2013) Critical role of neuronal pentraxin 1 in mitochondria-mediated hypoxic-ischemic neuronal injury. Neurobiol Dis 50:59-68. https://doi.org/10. 1016/j.nbd.2012.10.003

Rajkumar AP, Christensen JH, Mattheisen M, Jacobsen I, Bache I, Pallesen J, Grove J, Qvist P, McQuillin A, Gurling HM, Tümer Z, Mors O, Børglum AD (2015) Analysis of t $(9 ; 17)$ (q33.2;q25.3) chromosomal breakpoint regions and genetic association reveals novel candidate genes for bipolar disorder. Bipolar Disord 17:205-211. https://doi.org/10.1111/bdi.12239

Rascovsky K, Hodges JR, Knopman D, Mendez MF, Kramer JH, Neuhaus J, van Swieten JC, Seelaar H, Dopper EGP, Onyike CU, Hillis AE, Josephs KA, Boeve BF, Kertesz A, Seeley WW, Rankin KP, Johnson JK, Gorno-Tempini M-L, Rosen H, Prioleau-Latham CE, Lee A, Kipps CM, Lillo P, Piguet O, Rohrer JD, Rossor MN, Warren JD, Fox NC, Galasko D, Salmon DP, Black SE, Mesulam M, Weintraub S, Dickerson BC, DiehlSchmid J, Pasquier F, Deramecourt V, Lebert F, Pijnenburg Y, Chow TW, Manes F, Grafman J, Cappa SF, Freedman M, Grossman M, Miller BL (2011) Sensitivity of revised diagnostic criteria for the behavioural variant of frontotemporal dementia. Brain 134:2456-2477. https://doi.org/10.1093/brain/ awr179

Reddy PH, Mani G, Park BS, Jacques J, Murdoch G, Whetsell W, Kaye J, Manczak M (2005) Differential loss of synaptic proteins in Alzheimer's disease: impl. J Alzheimers Dis 7:103-117. https:// doi.org/10.3233/jad-2005-7203

Remnestål J, Öijerstedt L, Ullgren A, Olofsson J, Bergström S, Kultima K, Ingelsson M, Kilander L, Uhlén M, Månberg A, Graff C, Nilsson P (2020) Altered levels of CSF proteins in patients with FTD, presymptomatic mutation carriers and non-carriers. Transl Neurodegener 9:27. https://doi.org/10.1186/s40035-020-00198-y

Reti IM, Reddy R, Worley PF, Baraban JM (2002) Prominent Narp expression in projection pathways and terminal fields. J
Neurochem 82:935-944. https://doi.org/10.1046/j.1471-4159. 2002.01051.x

Ringman JM, Schulman H, Becker C, Jones T, Bai Y, Immermann F, Cole G, Sokolow S, Gylys K, Geschwind DH, Cummings JL, Wan HI (2012) Proteomic changes in cerebrospinal fluid of presymptomatic and affected persons carrying familial Alzheimer disease mutations. Arch Neurol 69:96-104. https://doi.org/10. 1001/archneurol.2011.642

Ruden JB, Dugan LL, Konradi C (2021) Parvalbumin interneuron vulnerability and brain disorders. Neuropsychopharmacology 46:279-287. https://doi.org/10.1038/s41386-020-0778-9

Rui Y, Gu J, Yu K, Hartzell HC, Zheng JQ (2010) Inhibition of AMPA receptor trafficking at hippocampal synapses by $\beta$-amyloid oligomers: the mitochondrial contribution. Mol Brain 3:10. https:// doi.org/10.1186/1756-6606-3-10

Scheff SW, Price DA, Schmitt FA, DeKosky ST, Mufson EJ (2007) Synaptic alterations in CA1 in mild Alzheimer disease and mild cognitive impairment. Neurology 68:1501-1508. https://doi.org/ 10.1212/01.wnl.0000260698.46517.8f

Schlimgen AK, Helms JA, Vogel H, Perin MS (1995) Neuronal pentraxin, a secreted protein with homology to acute phase proteins of the immune system. Neuron 14:519-526. https://doi.org/10. 1016/0896-6273(95)90308-9

Schmidt T, Samaras P, Frejno M, Gessulat S, Barnert M, Kienegger H, Krcmar H, Schlegl J, Ehrlich H-C, Aiche S, Kuster B, Wilhelm M (2018) ProteomicsDB. Nucleic Acids Res 46:D1271-D1281. https://doi.org/10.1093/nar/gkx1029.Accessed28May2021

Schwarz DA, Barry G, Mackay KB, Manu F, Naeve GS, Vana AM, Verge G, Conlon PJ, Foster AC, Maki RA (2002) Identification of differentially expressed genes induced by transient ischemic stroke. Brain Res Mol Brain Res 101:12-22. https://doi.org/10. 1016/s0169-328x(02)00135-3

Selkoe DJ (2002) Alzheimer's disease is a synaptic failure. Science 298:789-791. https://doi.org/10.1126/science.1074069

Senior AW, Evans R, Jumper J, Kirkpatrick J, Sifre L, Green T, Qin C, Žídek A, Nelson AWR, Bridgland A, Penedones H, Petersen S, Simonyan K, Crossan S, Kohli P, Jones DT, Silver D, Kavukcuoglu K, Hassabis D (2020) Improved protein structure prediction using potentials from deep learning. Nature 577:706-710. https:// doi.org/10.1038/s41586-019-1923-7

Shepherd JD, Rumbaugh G, Wu J, Chowdhury S, Plath N, Kuhl D, Huganir RL, Worley PF (2006) Arc/Arg3.1 mediates homeostatic synaptic scaling of AMPA receptors. Neuron 52:475-484. https://doi.org/10.1016/j.neuron.2006.08.034

Shrive AK, Cheetham GM, Holden D, Myles DA, Turnell WG, Volanakis JE, Pepys MB, Bloomer AC, Greenhough TJ (1996) Three dimensional structure of human C-reactive protein. Nat Struct Biol 3:346-354. https://doi.org/10.1038/nsb0496-346

Sia G-M, Béique J-C, Rumbaugh G, Cho R, Worley PF, Huganir RL (2007) Interaction of the N-terminal domain of the AMPA receptor GluR4 subunit with the neuronal pentraxin NP1 mediates GluR4 synaptic recruitment. Neuron 55:87-102. https://doi.org/ 10.1016/j.neuron.2007.06.020

Soldan A, Moghekar A, Walker KA, Pettigrew C, Hou X, Lu H, Miller MI, Alfini A, Albert M, Xu D, Xiao M-F, Worley P (2019) Resting-state functional connectivity is associated with cerebrospinal fluid levels of the synaptic protein NPTX2 in non-demented older adults. Front Aging Neurosci 11:132. https://doi.org/10. 3389/fnagi.2019.00132

Song Z, Xu Y, Deng W, Zhang L, Zhu H, Yu P, Qu Y, Zhao W, Han Y, Qin C (2020) Brain derived exosomes are a double-edged sword in Alzheimer's disease. Front Mol Neurosci 13:79. https://doi. org/10.3389/fnmol.2020.00079

Spellman DS, Wildsmith KR, Honigberg LA, Tuefferd M, Baker D, Raghavan N, Nairn AC, Croteau P, Schirm M, Allard R, Lamontagne J, Chelsky D, Hoffmann S, Potter WZ (2015) Development 
and evaluation of a multiplexed mass spectrometry based assay for measuring candidate peptide biomarkers in Alzheimer's Disease Neuroimaging Initiative (ADNI) CSF. Proteomics Clin Appl 9:715-731. https://doi.org/10.1002/prca.201400178

Südhof TC (2018) Towards an understanding of synapse formation. Neuron 100:276-293. https://doi.org/10.1016/j.neuron.2018.09. 040

Suzuki K, Elegheert J, Song I, Sasakura H, Senkov O, Matsuda K, Kakegawa W, Clayton AJ, Chang VT, Ferrer-Ferrer M, Miura E, Kaushik R, Ikeno M, Morioka Y, Takeuchi Y, Shimada T, Otsuka S, Stoyanov S, Watanabe M, Takeuchi K, Dityatev A, Aricescu AR, Yuzaki M (2020) A synthetic synaptic organizer protein restores glutamatergic neuronal circuits. Science 369:4853. https://doi.org/10.1126/science.abb4853

Swanson A, Willette AA, Alzheimer's Disease Neuroimaging Initiative (2016) Neuronal Pentraxin 2 predicts medial temporal atrophy and memory decline across the Alzheimer's disease spectrum. Brain Behav Immun 58:201-208. https://doi.org/10.1016/j.bbi. 2016.07.148

Swanson A, Wolf T, Sitzmann A, Willette AA (2018) Neuroinflammation in Alzheimer's disease: pleiotropic roles for cytokines and neuronal pentraxins. Behav Brain Res 347:49-56. https://doi.org/10.1016/j. bbr.2018.02.015

Swift IJ, Sogorb-Esteve A, Heller C, Synofzik M, Otto M, Graff C, Galimberti D, Todd E, Heslegrave AJ, van der Ende EL, Van Swieten JC, Zetterberg H, Rohrer JD (2021) Fluid biomarkers in frontotemporal dementia: past, present and future. J Neurol Neurosurg Psychiatry 92:204-215. https://doi.org/10.1136/jnnp-2020-323520

Takahashi H, Brasnjevic I, Rutten BPF, Van Der Kolk N, Perl DP, Bouras C, Steinbusch HWM, Schmitz C, Hof PR, Dickstein DL (2010) Hippocampal interneuron loss in an APP/PS1 double mutant mouse and in Alzheimer's disease. Brain Struct Funct 214:145160. https://doi.org/10.1007/s00429-010-0242-4

Tenner AJ, Stevens B, Woodruff TM (2018) New tricks for an ancient system: physiological and pathological roles of complement in the CNS. Mol Immunol 102:3-13. https://doi.org/10.1016/j.molimm. 2018.06.264

Terry RD, Masliah E, Salmon DP, Butters N, DeTeresa R, Hill R, Hansen LA, Katzman R (1991) Physical basis of cognitive alterations in Alzheimer's disease: synapse loss is the major correlate of cognitive impairment. Ann Neurol 30:572-580. https://doi.org/10.1002/ ana. 410300410

Thannickal TC, Lai Y-Y, Siegel JM (2007) Hypocretin (orexin) cell loss in Parkinson's disease. Brain 130:1586-1595. https://doi.org/10. 1093/brain/awm097

The UniProt Consortium (2021) UniProt: the universal protein knowledgebase in 2021. Nucleic Acids Res 49:D480-D489. https://doi. org/10.1093/nar/gkaa1100.Accessed28April2021

Tseng LA, Bixby JL (2011) Interaction of an intracellular pentraxin with a BTB-Kelch protein is associated with ubiquitylation, aggregation and neuronal apoptosis. Mol Cell Neurosci 47:254-264. https://doi. org/10.1016/j.mcn.2011.04.005

Tsui CC, Copeland NG, Gilbert DJ, Jenkins NA, Barnes C, Worley PF (1996) Narp, a novel member of the pentraxin family, promotes neurite outgrowth and is dynamically regulated by neuronal activity. J Neurosci 16:2463-2478

Uhlén M, Fagerberg L, Hallström BM, Lindskog C, Oksvold P, Mardinoglu A, Sivertsson A, Kampf C, Sjöstedt E, Asplund A, Olsson I, Edlund K, Lundberg E, Navani S, Szigyarto CA-K, Odeberg J, Djureinovic D, Takanen JO, Hober S, Alm T, Edqvist P-H, Berling H, Tegel H, Mulder J, Rockberg J, Nilsson P, Schwenk JM, Hamsten M, Feilitzen K von, Forsberg M, Persson L, Johansson F, Zwahlen M, Heijne G von, Nielsen J, Pontén F (2015) Tissue-based map of the human proteome. Science. https://doi.org/10.1126/scien ce.1260419. Protein Atlas. http://www.proteinatlas.org. Accessed 28 Apr 2021 van der Ende EL, Meeter LH, Stingl C, van Rooij JGJ, Stoop MP, Nijholt DAT, Sanchez-Valle R, Graff C, Öijerstedt L, Grossman M, McMillan C, Pijnenburg YAL, Laforce R, Binetti G, Benussi L, Ghidoni R, Luider TM, Seelaar H, van Swieten JC (2019) Novel CSF biomarkers in genetic frontotemporal dementia identified by proteomics. Ann Clin Transl Neurol 6:698-707. https://doi.org/10.1002/ acn3.745

van der Ende EL, Xiao M, Xu D, Poos JM, Panman JL, Jiskoot LC, Meeter LH, Dopper EG, Papma JM, Heller C, Convery R, Moore K, Bocchetta M, Neason M, Peakman G, Cash DM, Teunissen CE, Graff C, Synofzik M, Moreno F, Finger E, Sánchez-Valle R, Vandenberghe R, Masellis M, Tartaglia MC, Rowe JB, Butler CR, Ducharme S, Gerhard A, Danek A, Levin J, Pijnenburg YA, Otto M, Borroni B, Tagliavini F, de Mendonca A, Santana I, Galimberti D, Seelaar H, Rohrer JD, Worley PF, van Swieten JC (2020) Neuronal pentraxin 2: a synapse-derived CSF biomarker in genetic frontotemporal dementia. J Neurol Neurosurg Psychiatry 91:612621. https://doi.org/10.1136/jnnp-2019-322493

Verret L, Mann EO, Hang GB, Barth AMI, Cobos I, Ho K, Devidze N, Masliah E, Kreitzer AC, Mody I, Mucke L, Palop JJ (2012) Inhibitory interneuron deficit links altered network activity and cognitive dysfunction in Alzheimer model. Cell 149:708-721. https://doi.org/ 10.1016/j.cell.2012.02.046

Walsh DM, Selkoe DJ (2004) Deciphering the molecular basis of memory failure in Alzheimer's disease. Neuron 44:181-193. https://doi.org/ 10.1016/j.neuron.2004.09.010

Wang Z, Wang X, Zou H, Dai Z, Feng S, Zhang M, Xiao G, Liu Z, Cheng Q (2020) The basic characteristics of the pentraxin family and their functions in tumor progression. Front Immunol 11:1757. https:// doi.org/10.3389/fimmu.2020.01757

Waterhouse A, Bertoni M, Bienert S, Studer G, Tauriello G, Gumienny R, Heer FT, de Beer TAP, Rempfer C, Bordoli L, Lepore R, Schwede T (2018) SWISS-MODEL: homology modelling of protein structures and complexes. Nucleic Acids Res 46:W296-W303. https:// doi.org/10.1093/nar/gky427.Accessed28April2021

Wellington H, Paterson RW, Portelius E, Törnqvist U, Magdalinou N, Fox NC, Blennow K, Schott JM, Zetterberg H (2016) Increased CSF neurogranin concentration is specific to Alzheimer disease. Neurology 86:829-835. https://doi.org/10.1212/WNL.0000000000 002423

Whitehead AS, Bruns GA, Markham AF, Colten HR, Woods DE (1983) Isolation of human $\mathrm{C}$-reactive protein complementary DNA and localization of the gene to chromosome 1. Science 221:69-71. https://doi.org/10.1126/science.6857266

Wibrand K, Messaoudi E, Håvik B, Steenslid V, Løvlie R, Steen VM, Bramham CR (2006) Identification of genes co-upregulated with Arc during BDNF-induced long-term potentiation in adult rat dentate gyrus in vivo. Eur J Neurosci 23:1501-1511. https://doi.org/ 10.1111/j.1460-9568.2006.04687.x

Wildsmith KR, Schauer SP, Smith AM, Arnott D, Zhu Y, Haznedar J, Kaur S, Mathews WR, Honigberg LA (2014) Identification of longitudinally dynamic biomarkers in Alzheimer's disease cerebrospinal fluid by targeted proteomics. Mol Neurodegeneration 9:22. https://doi.org/10.1186/1750-1326-9-22

Williams JH, Wilcock GK, Seeburger J, Dallob A, Laterza O, Potter W, Smith AD (2011) Non-linear relationships of cerebrospinal fluid biomarker levels with cognitive function: an observational study. Alzheimers Res Ther 3:5. https://doi.org/10.1186/alzrt64

Wong YC, Krainc D (2017) $\alpha$-synuclein toxicity in neurodegeneration: mechanism and therapeutic strategies. Nat Med 23:1-13. https:// doi.org/10.1038/nm.4269

Xiao M-F, Xu D, Craig MT, Pelkey KA, Chien CC, Shi Y, Zhang J, Resnick S, Pletnikova O, Salmon D, Brewer J, Edland S, Wegiel J, Tycko B, Savonenko A, Reeves RH, Troncoso JC, McBain CJ, Galasko D, Worley PF (2017) NPTX2 and cognitive dysfunction 
in Alzheimer's Disease. Life 6:1-27. https://doi.org/10.7554/eLife. 23798

Xu D, Hopf C, Reddy R, Cho RW, Guo L, Lanahan A, Petralia RS, Wenthold RJ, O'Brien RJ, Worley P (2003) Narp and NP1 form heterocomplexes that function in developmental and activity-dependent synaptic plasticity. Neuron 39:513-528. https://doi.org/10.1016/ s0896-6273(03)00463-X

Xu Y, Zhao M, Han Y, Zhang H (2020) GABAergic Inhibitory Interneuron Deficits in Alzheimer's Disease: Implications for Treatment. Front Neurosci 14:660. https://doi.org/10.3389/fnins.2020.00660
Yin GN, Lee HW, Cho J-Y, Suk K (2009) Neuronal pentraxin receptor in cerebrospinal fluid as a potential biomarker for neurodegenerative diseases. Brain Res 1265:158-170. https://doi.org/10.1016/j.brain res.2009.01.058

Yuzaki M (2018) Two classes of secreted synaptic organizers in the central nervous system. Annu Rev Physiol 80:243-262. https://doi.org/ 10.1146/annurev-physiol-021317-121322

Publisher's Note Springer Nature remains neutral with regard to jurisdictional claims in published maps and institutional affiliations. 